\title{
Hallmarks of glycogene expression and glycosylation pathways in squamous and adenocarcinoma cervical cancer
}

Patricia Martinez-Morales ${ }^{1}$, Irene Morán Cruz ${ }^{2}$, Lorena Roa-de la Cruz ${ }^{3}$, Paola Maycotte ${ }^{4}$, Juan Salvador Reyes Salinas $^{5}$, Victor Javier Vazquez Zamora ${ }^{5}$, Claudia Teresita Gutierrez Quiroz ${ }^{5}$, Alvaro Jose Montiel-Jarquin ${ }^{5}$, Verónica Vallejo-Ruiz ${ }^{\text {Corresp. } 2}$

${ }^{1}$ CONACYT-Centro de Investigación Biomédica de Oriente, Mexican Institute of Social Security, Metepec, Puebla, México

${ }^{2}$ Centro de Investigación Biomédica de Oriente, Laboratory of Molecular Biology, Instituto Mexicano del Seguro Social, Metepec, Puebla, México

3 Department of Biological Chemical Sciences, Universidad de las Américas - Puebla, San Andrés Cholula, Puebla, Mexico

${ }^{4}$ Centro de Investigación Biomédica de Oriente, Laboratory of Cell Biology, Instituto Mexicano del Seguro Social, Metepec, Puebla, México

5 Hospital de especialidades, General Manuel Ávila Camacho, Instituto Mexicano del Seguro Social, Puebla, Puebla, México

Corresponding Author: Verónica Vallejo-Ruiz

Email address: veronica.vallejor@imss.gob.mx

Background: Dysregulation of glycogene expression in cancer can lead to aberrant glycan expression, which can promote tumorigenesis. Cervical cancer (CC) displays an increased expression of glycogenes involved in sialylation and sialylated glycans. Here, we show a comprehensive analysis of glycogene expression in CC to identify glycogene expression signatures and the possible glycosylation pathways altered. Methods: First, we performed a microarray expression assay to compare glycogene expression changes between normal and cervical cancer tissues. Second, we used 401 glycogenes to analyze glycogene expression in adenocarcinoma and squamous carcinoma from RNA-seq data at the cBioPortal for Cancer Genomics. Results: The analysis of the microarray expression assay indicated that CC displayed an increase in glycogenes related to GPI-anchored biosynthesis and a decrease in genes associated with chondroitin and dermatan sulfate with respect to normal tissue. Also, the glycogene analysis of CC samples by the RNA-seq showed that the glycogenes involved in the chondroitin and dermatan sulfate pathway were downregulated. Interestingly the adenocarcinoma tumors displayed a unique glycogene expression signature compared to squamous cancer that shows heterogeneous glycogene expression divided into six types. Squamous carcinoma type 5 (SCC-5) showed increased expression of genes implicated in keratan and heparan sulfate synthesis, glycosaminoglycan degradation, ganglio, and globo glycosphingolipid synthesis was related to poorly differentiated tumors and poor survival. Squamous carcinoma type 6 (SCC-6) displayed an increased expression of genes involved in chondroitin/dermatan sulfate synthesis and lacto and neolacto glycosphingolipid synthesis and was associated with nonkeratinizing squamous cancer and good survival . In summary, our study showed 
that CC tumors are not a uniform entity, and their glycome signatures could be related to different clinicopathological characteristics. 
1 Hallmarks of glycogene expression and glycosylation pathways in squamous and 2 adenocarcinoma cervical cancer

3

4

5

6

7

8

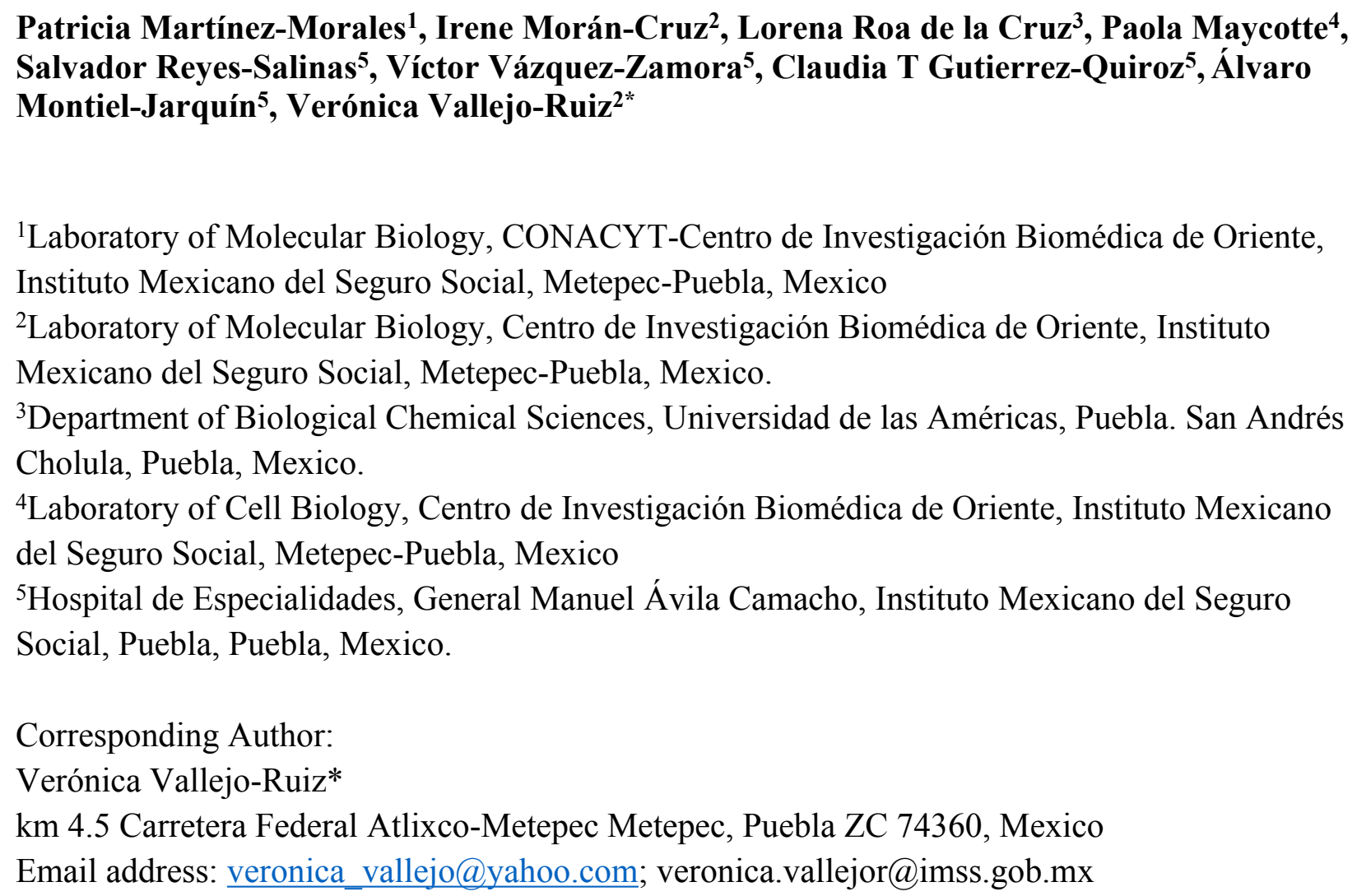

\section{Abstract}

Background: Dysregulation of glycogene expression in cancer can lead to aberrant glycan expression, which can promote tumorigenesis. Cervical cancer (CC) displays an increased expression of glycogenes involved in sialylation and sialylated glycans. Here, we show a comprehensive analysis of glycogene expression in CC to identify glycogene expression signatures and the possible glycosylation pathways altered.

Methods: First, we performed a microarray expression assay to compare glycogene expression changes between normal and cervical cancer tissues. Second, we used 401 glycogenes to analyze glycogene expression in adenocarcinoma and squamous carcinoma from RNA-seq data at the cBioPortal for Cancer Genomics.

Results: The analysis of the microarray expression assay indicated that CC displayed an increase in glycogenes related to GPI-anchored biosynthesis and a decrease in genes associated with chondroitin and dermatan sulfate with respect to normal tissue. Also, the glycogene analysis of CC samples by the RNA-seq showed that the glycogenes involved in the chondroitin and dermatan sulfate pathway were downregulated. Interestingly the adenocarcinoma tumors displayed a unique glycogene expression signature compared to squamous cancer that shows 
42 heterogeneous glycogene expression divided into six types. Squamous carcinoma type 5 (SCC-5)

43 showed increased expression of genes implicated in keratan and heparan sulfate synthesis,

44 glycosaminoglycan degradation, ganglio, and globo glycosphingolipid synthesis was related to

45 poorly differentiated tumors and poor survival. Squamous carcinoma type 6 (SCC-6) displayed

46 an increased expression of genes involved in chondroitin/dermatan sulfate synthesis and lacto

47 and neolacto glycosphingolipid synthesis and was associated with nonkeratinizing squamous

48 cancer and good survival. In summary, our study showed that $\mathrm{CC}$ tumors are not a uniform

49 entity, and their glycome signatures could be related to different clinicopathological

50 characteristics.

51

52

53

54

55

56

57

58

59

60

61

62

63

64

65

66

67

68

69

70

71

72

73

74

75

76

77

78

79

80

81

\section{Introduction}

Cervical cancer (CC) is one of the leading causes of cancer-related death in women worldwide (IARC, 2020). According to the histological origin, the most frequent types of CC are squamous cell carcinoma (SCC) and adenocarcinoma (AC) in $80 \%$ and $15-20 \%$ of cases, respectively (Chavarro et al., 2009). A recent multi-omic molecular characterization of CC leads to the molecular classification into keratin-low squamous, keratin-high squamous, and adenocarcinoma-rich cancer (TCGA, 2017), suggesting that CC is not a uniform entity. In this context, the glycome of CC may also be diverse.

Glycogenes, or genes associated with glycan synthesis, include those genes implicated in the glycosylation pathways, such as glycosyltransferases and glycosidases, and genes necessary for glycosynthesis, such as sugar-nucleotide synthases, sugar-nucleotide transporters, chaperones, genes necessary for glycolysis (A. Sachiko and A. Kiyohiko 2019; Schjoldager et al., 2020). Several studies support that cancer displays an aberrant expression of those glycogenes implicated in glycosylation (Pinho et al., 2015; Schjoldager et al., 2020); and certainly, changes in the expression of glycogenes or cell surface glycans have been related to cancer progression and prognosis (Kannagi et al., 2008; Pinho et al., 2012; Pinho et al., 2015; Mukley et al., 2016; Zhuo et al., 2018; Schjoldager et al., 2020; Yip et al., 2006; Liu et al., 2010; Cordeiro et al., 2015; Li et al., 2017; Lin et al., 2018; Salustiano et al., 2020). In this context, in silico models predicting cellular glycosylation are important for addressing the cancer glycome (Schjoldager et al., 2020).

Several reports indicate that cervical dysplasia and CC display increased expression of the glycan-cell surface sialyl Lewis A (SLeA) and sialyl Lewis X (SLeX) Roy et al., 2005; LopezMorales et al., 2010; Engelstaedter et al., 2012; Velazquez-Marquez et al., 2012; Jin et al., 2016) and polylactosamine and the O-glycosylated antigens Tn and sialyl-Tn (Numa 1995; Clark et al., 2014). Even the expression of the Tn antigen correlates with metastatic potential and poor prognoses (Numa 1995). In concordance, the expression of sialyltransferases ST3Gal III and ST6Gal I is increased in premalignant lesions and CC (Wang et al., 2001; Wang et al., 2002; 
Lopez-Morales et al., 2009). Even a high expression of the glycogene ST6GAL1 correlates with stromal invasion, metastatic spread to the lymph nodes, and poor patient prognosis (Wang et al., 2002; Wang et al., 2003). Concerning polylactosamine synthesis, the expression of the polylactosamine synthase $\beta 3 \mathrm{GnT} 2$ is increased in high-grade premalignant lesions (Clark et al., 2014), while the expression of the glycogene B4GALT3 is upregulated in CC (Sun et al., 2016). Other changes include the decrease of fucosylation level as the grade of cervical dysplasia increases (Jin et al., 2016). Here, to obtain comprehensive scenery of the CC glycome and a glycogene signature related to the clinicopathological characteristics and prognosis, we first compared the glycogene expression in $\mathrm{CC}$ with the normal cervix and then between the histological types of AC and SCC.

\section{Materials \& Methods}

\section{Patient samples}

The Ethics Committee approved the present study of the Instituto Mexicano del Seguro Social (R-2012-785-061). All patients signed an informed consent form according to the guidelines of the Human Ethics Committee. Biopsies were obtained at the Hospital de Especialidades, General Manuel Ávila Camacho, Instituto Mexicano del Seguro Social from women between the ages of 20 and 73. For the CC group, inclusion criteria included adult women with SC diagnosis with no previous treatment (mean age 42). In contrast, for the normal cervix group, samples were obtained from adult women with uterine myomatosis diagnosis (mean age 35). A total of $23 \mathrm{CC}$ samples and 15 biopsies of normal cervical tissue were included in the analysis.

\section{Microarray assay}

Normal cervix tissues and CC samples were collected and maintained in RNAlater solution (Qiagen, Hilden, Germany) at $-80^{\circ} \mathrm{C}$. Total RNA was extracted using the RNeasy Plus system (Qiagen, Hilden, Germany) following the manufacturer's protocol. RNA samples were pooled into two groups (normal and CC). Microarray analysis was performed at the Microarray Unit of the Instituto de Fisiología Celular, Universidad Nacional Autónoma de México (UNAM). Ten micrograms of total RNA were used to synthesize labeled cDNA employing the First-Strand cDNA labeling kit (Invitrogen, United States), incorporating dUTP-Alexa555 or dUTPAlexa647. Equal quantities of labeled cDNA were hybridized using IniHyb hybridization solution (TeleChem International INC). The microarray included 10,000 genes from the NCB and GenBank databases. Acquisition and quantification of array images were performed using a Scan Array 4000 instrument and ScanArray 4000 software (Packard BioChips, USA). The Alexa555 and Alexa647 density and background mean values were calculated with ArrayPro Analyzer software from Media Cybernetics. GenArise1.38.0 software developed in the Computing Unit of the Cellular Physiology Institute of UNAM was used for the data analysis 
122 and statistics. Analyzed data were submitted to the NCBI-Gene Expression Omnibus database

123 (accession number GSE159976).

124

125

126

127

128

129

130

131

132

133

134

135

136

137

138

139

140

141

142

143

144

145

146

147

148

149

150

151

152

153

154

155

156

157

158

159

160

161

\section{Glycogene expression analysis}

We selected glycogenes with a z-score $\geq \pm 2$ to identify the glycogenes with expression changes between the CC and normal cervix. A total of 401 glycogenes reported to date were used for glycogene expression analysis; these were obtained from the published reports of Venkitachalam et al., 2016, and Aco-Tlachi et al., 2018. Glycogenes included glycosyltransferases and glycosidases, sugar-nucleotide synthases, sugar-nucleotide transporters, chaperones, and some genes related with energetic metabolism.

\section{Protein-protein enrichment analysis}

Glycogenes identified as altered were submitted to the STRING database version 10.5 (http://string-db.org/) to evaluate predicted protein-protein interactions (Szklarczyk et al. 2018). We considered the following settings for the analysis: text mining, experiments, databases, coexpression, neighborhood, gene fusion, and cooccurrence as interaction sources, with no more than five interactors and a minimum interaction score of 0.4 as the confidence level. Biological process $(\mathrm{GO})$ and KEGG pathways were chosen as functional enrichments of the network. The results exclusively included a protein-protein enrichment $p$-value of at least $\leq 0.05$ and an FDR of at least $\leq 0.05$.

\section{RNA-seq data analysis}

RNA-seq data of 401 glycogenes from TCGA and Firehose Legacy were obtained from the cBioPortal for Cancer Genomics (Gao et al. 2013). We analyzed glycogene expression considering the mRNA expression of genes with a z-score threshold \pm 2.0 relative to all samples ( $\log$ RNA Seq V2 RSEM). The population included women from 20 to 88 with a diagnosis of SCC and AC, four samples of cervical adenosquamous carcinoma, and all the group stages from I to IVB (AJCC staging system).

\section{Hierarchical clustering}

Clinical data of patients obtained from the cBioPortal for Cancer Genomics and their respective RNA-seq data of glycogene expression were organized and submitted in the online free software Morpheus (https://software.broadinstitute.org/morpheus/) to perform the heat map analysis and hierarchical clustering. One minus Pearson correlation was used as the metric, and the average was used as the linkage method. Venn diagram of glycogenes clusters were obtained using the tool http://bioinformatics.psb.ugent.be/webtools/Venn/. 
162

163

164

165

166

167

168

169

170

171

172

173

174

175

176

177

178

179

180

181

182

183

184

185

186

187

188

189

190

191

192

193

194

195

196

197

198

199

200

201

\section{Pathway enrichment analysis}

Altered glycogenes were analyzed using DAVID (Database for Annotation, Visualization, and Integrated Discovery) software (http://david.abcc.ncifcrf.gov/). Based on gene ontology (GO), genes were classified according to their function in the KEGG pathway with at least a p-value $<$ 0.05 and FDR $<0.05$.

\section{Results}

\section{Comparison of glycogene expression between cervical cancer and healthy cervical tissue}

We performed a microarray expression assay to identify changes in glycogene expression in CC compared to a normal cervix. From the 178 glycogenes contained in the microarray, results indicated that 15 glycogenes were altered in $\mathrm{CC}$ (z-score threshold \pm 2.0$)$. The glycogenes PIGC, PIGN, SMPD3, CHI3L1, HEXB, and ST6GAL1 were upregulated (Table supp 1-column A), and GYS1, CHST12, CTBS, HAS3, HPSE, HYAL2, GALNT11, $U G T 2 B 4$, and UGT2B28 were downregulated (Table supp 2-column A). Bibliographic research indicates that most altered glycogenes are reported to have expression changes in other types of cancer (Table 1 and Table 2).

Then, to further map the 15 altered genes onto the global glycogene network, we performed a protein-protein interaction (PPI) network functional analysis in the STRING database (Szklarczyk et al. 2018) using the 401 glycogenes (Figure supp 1A). Results showed a complex interaction among the 401 glycogenes, since some of them were involved in several glycosylation pathways (Figure supp 1B, 1C, 1F). Thus, we refine the search for identification of specific glycosylation pathways by performing a PPI analysis, including only the upregulated and downregulated glycogenes. The glycogenes SMPD3, CHI3L1, HEXB, and ST6GAL1, were involved in the immune system response (p-value $\leq 0.005$ ), while $P I G C$ and $P I G N$ participate in the synthesis of GPI anchors (Figure 1A). In contrast, results revealed that HYAL2 and HAS3 were involved in the hyaluronan (HA) metabolic process. To further identify putative targets and additional glycosylation pathways not displayed in the previous analysis, we included the upregulated or downregulated glycogenes and five more interactors in the subsequent analysis. The results again showed that $P I G C$ and $P I G N$ were involved in synthesizing GPI anchors (Figure 1C). In contrast, CHI3L1 and $H E X B$, together with FUCA2 and $H E X A$, were engaged in neutrophil degranulation (p-value $\leq 0.001$ ) (Figure 1C). Concerning the downregulated glycogenes, UGT2B4 and UGT2B28, along with UGP2, were implicated in pentose and glucuronate interconversions ( $\mathrm{p}$-value $\leq 0.001$ ) (Figure 1D). Other results showed that CHST12 could interact with CHST3 and CHST7 in chondroitin sulfate $(\mathrm{CS}) /$ dermatan sulfate synthesis ( $\mathrm{p}$-value $\leq 0.001$ ) (Figure 1D).

Peer) reviewing PDF | (2021:05:60970:1:1:NEW 27 Jul 2021) 


\section{Comparison between adenocarcinoma and squamous cervical}

204

205

206

207

208

209

210

211

212

213

214

215

216

217

218

219

220

221

222

223

224

225

226

227

228

229

230

231

232

233

234

235

236

237

238

239

240

241
Next, to identify glycogene signatures in CC, we analyzed the expression of 401 glycogenes in 297 samples using the RNA-seq public data obtained from the cBioPortal for Cancer Genomics using the samples that corresponded to the histological types of SC and AC (Table 3). Unsupervised hierarchal clustering analysis revealed that 25 genes exhibited low expression in almost all samples compared with the rest of the glycogenes (Table supp 2-column B), suggesting a hallmark of glycogene expression among all CC types.

Then, to test whether AC and SCC could display distinctive glycogene expression, we compared the gene expression between them. The results showed differences in glycogene expression. Samples of SCC displayed a heterogeneous pattern of gene expression (Figure 2A). In contrast, $\mathrm{AC}$ displayed characteristic glycogene expression that included 107 glycogenes grouped into three different clusters: AC-A, AC-B, and AC-C (Figure 2A). Cluster AC-A included 51 genes with a high expression (Figure 2A; Table supp 1-column B), while AC-B and AC-C displayed low gene expression of 23 and 33 glycogenes (Table supp 2-column $\mathrm{C}$ and column D), respectively, compared with the rest of the $\mathrm{CC}$ population (Figure 2A). The results of the functional analysis revealed that glycogenes in the AC-A cluster participate in N-glycan biosynthesis, mucin-type O-glycan biosynthesis, glycosphingolipid biosynthesis (lacto and neolacto series), GAG biosynthesis keratan sulfate (KS), glycosphingolipid biosynthesis (globo and ganglio series), other glycan degradation, and other pathways, such as amino sugar and nucleotide sugar metabolism, starch and sucrose metabolism, and carbohydrate digestion and absorption (Figure 2B). In comparison, genes with a low expression in AC-B are involved in GAG biosynthesis (CS, dermatan sulfate (DS)) and heparan sulfate/heparin (HS), mucin-type Oglycan biosynthesis, and metabolic pathways (Figure 2C). Similarly, glycogenes in cluster AC-C were implicated in metabolic pathways and biosynthesis of CS, DS, HS but also GPI-anchor biosynthesis, glycosphingolipid biosynthesis (lacto and neolacto series), galactose metabolism, GAG degradation, and other pathways, such as amino sugar and nucleotide sugar metabolism, starch and sucrose metabolism, and insulin signaling pathways (Figure 2D).

We further compared the glycogene expression of adenosquamous carcinoma with AC and SCC since the histological type includes both adenoid and squamous cells from the origin.

\section{Identification of hallmark glycogenes in squamous cervical cancer}

To further identify a glycogene expression hallmark in SCC, we removed the 20 glycogenes with low expression in all the $\mathrm{CC}$ samples and performed an unsupervised hierarchal clustering analysis exclusively in SCC samples $(n=253)$. The results indicate that almost all SCC samples 
242

243

244

245

246

247

248

249

250

251

252

253

254

255

256

257

258

259

260

261

262

263

264

265

266

267

268

269

270

271

272

273

274

275

276

277

278

279

280

281

exhibit a low expression of CHIA, GLT6D1, SPACA3, FUT9, B3GALT1, GALNTL5, NEU2, $U G T 2 B 15, U G T 2 A 3, U G T 2 B 7$, and LYZL4 (Table supp 2-column E). Moreover, the results showed that two clusters of samples, SCC-1 and SCC-2, display specific glycogene expression (Figure 3A). SCC-1 comprised 29 samples that showed a cluster of 30 glycogenes with high expression (SCC-1A; Table supp 1-column C) and a cluster of 19 genes with low expression (SCC-1B) (Figure 3 and Table supp 2-column F). In contrast, SCC-2 formed by 36 samples exhibited a cluster of 31 genes with low expression (Figure 3A and Table supp 2-column G).

SCC-1 included samples with a diagnosis from stage I to stage III, but most of the samples were stage I, and patients displayed (Table 4) an $89 \%$ survival rate. Samples included moderately differentiated (G2) and poorly differentiated (G3) tumors (Table 4). Enrichment analysis showed that genes were impllicated in N-glycan biosynthesis, other types of O-glycan biosynthesis, GPIanchor biosynthesis, lysosomes, GAG degradation, biosynthesis of CS/DS and HS, and other processes, such as processes in the endoplasmic reticulum and amino sugar and nucleotide sugar metabolism (Figure 3C). Glycogenes in cluster SCC-1B were involved in N-glycan biosynthesis, CHS/DS biosynthesis, sphingolipid metabolism, and protein processing in the endoplasmic reticulum (Figure 3C).

Regarding cluster SCC-2 and the clinicopathological characteristics, most of the samples corresponded to stage I; however, two samples with a diagnosis of stage IV and comprised of differentiation grades from G1 (well-differentiated) to G3 were also included. Overall survival analysis showed that patients displayed an $88 \%$ survival rate (Table 4 ). The glycogenes were involved in CS/DS biosynthesis, GAG degradation, other glycan degradation, and glycosphingolipid biosynthesis (ganglio, globo, lacto and neolacto series), among others (Figure 3C). These results indicate that at least two types of SCC samples display a hallmark of glycogene expression. However, we cannot conclude a specific association with tumor characteristics or patient survival because not all the samples contained complete information.

Then, we evaluated individually whether cancer stage, molecular classification, tumor differentiation grade, or overall survival status were associated with a glycogene signature; however, the results did not show any glycogene expression pattern. These data indicate that glycogene expression is not individually associated with any of the abovementioned clinical features. To refine the analysis, we exclusively analyzed SCC samples that contained complete information: cancer stage, molecular classification, tumor differentiation grade, and overall survival status $(\mathrm{n}=158)$. The results showed that from 158 samples, 67 were organized into 4 clusters that displayed a specific glycogene expression pattern (Figure 4A). The first cluster included 25 patient samples (SCC-3); the second cluster included 23 samples (SCC-4); the third cluster included ten samples (SCC-5); and the fourth cluster included nine samples (SCC-6) (Figure 4A). Analysis of the clinical characteristics of clustered patient samples (Table 4) showed that SCC-3 tumors were stage I (56\%), with a nonkeratinizing molecular classification 
282 (68\%), a G3 differentiation grade (52\%), and a 68\% survival rate. Cluster SCC-5 was formed by

283

284

285

286

287

288

289

290

291

292

293

294

295

296

297

298

299

300

301

302

303

304

305

306

307

308

309

310

311

312

313

314

315

316

317

318

319

320

321 samples from stage I (90\%), with nonkeratinizing tumors in 70\%, a G3 differentiation grade in $80 \%$ of the cases, and patients displayed a 50\% survival rate. Concerning SCC- 6 , the cluster comprised only nonkeratinizing tumors with stages I to IV and an $88 \%$ survival rate (Table 4).

SCC-3 displayed a high expression of 6 glycogenes related to HS/heparin biosynthesis (Figure 3B; Table supp 1-column D; Figure supp 2C). SCC-5 showed a high expression of 9 glycogenes implicated in CS/DS biosynthesis and glycosphingolipid biosynthesis (lacto and neolacto series) (Figure 4C; Table supp 1-column F; Figure supp 2C). In contrast, SCC-6 exhibited a high expression of 42 glycogenes, some of which were involved in glycosphingolipid biosynthesis (ganglio and globo series) (Figure 4E; Table supp 1-column G; Figure supp 2C). Regarding SCC-4, the results showed two clusters of glycogenes, SCC-4A and SCC-4B, that corresponded to the same glycogenes in clusters SCC-1A and SCC-1B (Tables supp 1-column E and Tables supp 2-column F; Figure supp 2A). A characteristic of SCC-4 was the low expression of genes involved in glycosphingolipid biosynthesis (lacto and neolacto series) and the high expression of genes involved in GAG degradation (Figure 4D). In summary, all the data suggest that there are at least five types of SCC with distinguishable glycogene expression, where SCC-4 probably corresponds to SCC-1 since they share some samples and glycogenes (Table 5; Figure supp 2B).

\section{Discussion}

\section{Cervical cancer displays upregulation of glycogenes implicated in GPI synthesis and downregulation of genes related to hyaluronan metabolism compared to healthy tissue.}

The human genome contains approximately 700 gene-encoding enzymes, including transporters and chaperones required for the cellular glycosylation machinery, glycan modifications, and degradation (Schjoldager et al., 2020). In this study, we analyzed the expression of 401 glycogenes, previously reported in Venkitachalam et al., 2016 and Aco-Tlachi et al., 2018, to obtain the glycome scenario in CC. We first compared the gene expression between CC and healthy tissue, and then we reached the glycogene expression in AC and SCC. The first analysis allowed us to understand the general glycosylation changes during cell transformation. The second analysis allowed us to identify the glycogene signatures in AC and SCC.

A comparison between $\mathrm{CC}$ and normal tissue indicated that $\mathrm{CC}$ displays upregulation of glycogenes related to GPI synthesis and downregulation of genes associated with the metabolism of HA. Regarding GPI-anchor biosynthesis, glycolipids act as anchors to specific cell surface proteins called GPI-anchored proteins. In breast, bladder, and gastric cancer, the high expression of other GPI-anchor biosynthesis glycogenes, such as PIGU,PIGT, and PIGX, is associated with oncogenesis, poor prognosis, and tumorigenesis (Guo et al., 2004; Zhao et al., 2012; Gamage et al., 2013; Nakakido et al., 2016). Here, for the first time, we describe that in comparison with 
322 healthy tissue, CC also displays upregulation of two GPI-anchor biosynthesis glycogenes;

323

324

325

326

327

328

329

330

331

332

333

334

335

336

337

338

339

340

341

342

343

344

345

346

347

348

349

350

351

352

353

354

355

356

357

358

359

360

361 interestingly, a high expression of some GPI-anchored proteins has been reported in CC (Jing et al., 2012; Liu et al., 2017; Jöhrens et al., 2019). To know whether the increase of GPI-anchored proteins is due to the rise of GPI biosynthesis should be tested in the future. Concerning HA, CC displayed downregulation of HAS3 and HYAL2 in comparison with healthy tissue. In HA metabolism, hyaluronan synthases 1 and 2 synthesize high molecular weight HA, while the hyaluronan synthase 3 (encoded by $H A S 3$ ) synthesizes low molecular weight HA (Itano et al., 1999; Itano et al., 2002); in contrast, HA degradation is induced by a family of hyaluronidases including Hyal2 (Csoka et al., 2001; Kaneiwa et al., 2012). Some evidence in SCC indicates that patients with a good prognosis display abundant levels of HA compared with those with the worst prognosis (Sano et al., 1987). The accumulation of HA is typical in several types of cancers, and its levels directly correlate with increased malignancy and a poor prognosis (Passi et al., 2019). For example, in endometrial cancer, HYAL1 and HYAL2 are downregulated compared to healthy tissue, and this phenotype correlates with the accumulation of hyaluronan (Nykopp et al., 2010). Studies in animals indicate that HYAL2 or HYAL1 inhibits tumor growth and may control intercellular interactions (Wang et al., 2008). Examination of whether downregulation of HYAL2 could lead to HA accumulation can be interesting in CC. Concerning HAS3, it is unknown whether the low expression of $H A S 3$ leads to a specific decrease in low molecular HA synthesis. Still, the low expression is associated with a poor prognosis in urothelial carcinoma (Chang et al., 2015). Characterization of the content levels of high- or low-molecular-weight HA in CC can be interesting, especially because their effects are different in cancer cell behavior and chemotherapy resistance (Price et al., 2018; Tavianatou et al., 2019a; Tavianatou et al., 2019b;). In summary, the results suggest that CC may display an increase in the synthesis of GPI anchors and dysregulation in the metabolism of HA.

The results obtained by the microarray assay allowed us to understand the global changes from the normal cervix to a cancer stage, and some of them show some coherence with the RNAseq analysis. Thus, the low expression of UGT2B4 and UGT2B28 in CC, analyzed in the microarray assay, was also found in all CC samples in the RNAseq analysis (Table supp 2-column B). Moreover, the low expression of HAS3, HPSE, and GYS1 was found in the AC-B and AC-C clusters (Table supp 2-column $\mathrm{C}$ and column $\mathrm{D}$, respectively). In the same way, the high expression of ST6GAL1 was also found in the cluster AC-A (Table supp 1-column B). Despite these results, one limitation of our study is to validate the glycogene expression by RT-PCR. However, the validation can be difficult, since implies to have a previously characterized glycogene expression of the samples, considering the different glycogene signatures found in the SCC. Hence, the microarray assay of pooled samples allowed us to understand global changes of $\mathrm{CC}$ but not the molecular diversity of CC.

Adenocarcinoma displays unique glycogene expression, but squamous cancer shows at least five types of glycogene signatures. 
362

363

364

365

366

367

368

369

370

371

372

373

374

375

376

377

378

379

380

381

382

383

384

385

386

387

388

389

390

391

392

393

394

395

396

397

398

399

400
Genomics studies suggest that $\mathrm{CC}$ is not a unique entity from molecular and genetic viewpoints (TCGA 2017; Srinivasan et al., 2019). Molecular characterization of CC includes three subgroups: keratin-low squamous, keratin-high squamous, and adenocarcinoma-rich (TCGA 2017). Regarding the glycome, our result suggests that AC displays a unique glycogene expression signature distinguishable from SCC, which in turn displays at least five types of glycogene signatures. Results shown in this study could explain some of the results where certain glycogenes in CC display high expression while other are exhibit low expression (Varchalama et al., 2009), and even where some of them are associated with specific cancer characteristics associated with patient prognosis (Varchalama et al., 200; Wang et al., 2003).

First, we showed that AC displays a glycogene signature characterized by 42 glycogenes (Table 5; Table supp 3), where some of them, such as $A L G 11, A L G 9$, and B3GALT5, can be relevant for cancer patients (Yu et al., 2020; Liu et al., 2021; Liao et al., 2021). In comparison, SCC was characterized by a heterogenicity of glycogene expression that can be distinguished by a selective glycogene expression (Figure supp 2). The results suggest that the composition of characteristics such as tumor stage, differentiation grade, molecular characterization, and global patient survival comprise a global value related to the glycogene expression pattern. SCC-2 was characterized only by the low expression of glycogenes (Table supp 2-column G). Also, we identified four kinds of SCC. Type SCC-1/SCC-4 displayed, specifically, the expression of 38 glycogenes, while six glycogenes recognized SCC-3. In comparison, SCC-5 showed the expression of eight glycogenes, and SCC- 6 could be distinguished by 36 glycogenes (Table 5; Table supp 3). The glycogene signatures of SCC-1/4, SCC-2, and SCC-6 were associated with $88-89 \%$ of overall survival. In contrast, the glycogene signatures of SCC-3 and SCC-5 displayed $68 \%$ and $50 \%$ of overall survival, respectively. These results suggest that glycogenes $C H S T 2$, COLGALT1, DSE, EXT1, EXT2, and GALNT18 in SCC-3 can be helpful as a biomarker of prognostic. In addition, detecting high levels of CHST11, CHST15, and GFPT2 can also be useful as prognostic biomarkers since their increased expression is associated with $50 \%$ of overall survival (in SCC-5). In comparison, their low expression is associated with $88-89 \%$ of overall survival (SCC-2). Further characterization of protein expression levels characterization and their association with survival will be necessary to consider some key glycogenes as valuable biomarkers.

Regarding the different expression of glycogenes in SCC, the whole molecular context can affect the gene expression in CC: miRNA, methylation, signaling pathway signatures, structural aberration (Yang et al., 2009; Farkas et al., 2013; Votja et al., 2016; TCGA 2017) and the integrated HR-HPV genome (TCGA 2017; Aco-Tlachi et al., 2018; Cisneros-Ramírez et al., 2020; Gagliardi et al., 2020), which we did not explore.

Peer] reviewing PDF | (2021:05:60970:1:1:NEW 27 Jul 2021) 
401

402

403

404

405

406

407

408

409

410

411

412

413

414

415

416

417

418

419

420

421

422

423

424

425

426

427

428

429

430

431

432

433

434

435

436

437

438

439

440

\section{Glycogene expression diversity in $\mathrm{CC}$ and putative consequences in their glycosylation pathways}

Glycosylation changes in cancer can be due to changes in the availability and abundance of the sugar nucleotide donors and cofactors, altered enzyme activity, and to dysregulation at the transcriptional level of the glycogenes (Pinho et al., 2015; Schjoldager et al., 2020). The evidence shown here suggests that $\mathrm{CC}$ may display a glycome diversity due to variability in the glycogene expression, whether AC or certain SC types. Regarding AC, results indicate that it is characterized by the increase of genes implicated in KS biosynthesis, N-glycan biosynthesis, and glycosphingolipids genes related to ganglio and globo series. In contrast, AC displayed low expression of glycogenes involved in the CS/DS and HS biosynthesis, GAG degradation, and GPI-anchor biosynthesis (Figure 5). Regarding SC, KEGG analysis revealed that the SCC-2 displayed low expression of glycogenes implicated in the CHS biosynthesis, GAG degradation, and glycosphingolipids biosynthesis (Figure 5).

In comparison, SCC-1/SCC-4 displayed an increase in the glycogenes implicated in HS/heparin biosynthesis and GAG degradation (Figure 5). Type SCC-3 exhibited high expression of glycogenes implicated in HS/heparin biosynthesis (Figure 5). SCC-6 was distinguished by the high expression glycogenes involved in several glycosylation pathways including in HS and KS biosynthesis and glycosphingolipid biosynthesis of the ganglio and globo series (Figure 5). Finally, SCC-5 displayed the expression of eight glycogenes involved in CS/DS biosynthesis, glycosphingolipid biosynthesis of lacto and neolacto series, and mucin-type O-glycan biosynthesis (Figure 5). All the data suggest a putative glycome diversity in CC, and future studies can be directed to characterize glycoconjugates accompanied by a glycogene signature.

\section{Conclusions}

CC displays distinct molecular characteristics, and the evidence shown here suggests that the glycome can also be diverse. First, we showed that, in comparison with the cervix, CC displays upregulation of glycogenes involved in GPI synthesis and HA metabolism, suggesting a disruption in the type of molecular weight of HA. In addition, our results showed that AC displays a unique glycogene signature independent of SCC. Interestingly, adenosquamous carcinoma displayed the same signature as AC. In comparison, SCC displays a diversity of glycogene expression, and at least five types of SCC displayed unique glycogene signatures that can be distinguished from each other through a set of specific glycogenes. Notably, some types of SCC can be associated with certain tumor characteristics and patient survival.

Further analysis of the CC glycome will be necessary: First, to discern a possible association between glycogene expression and a value of the clinical characteristics of the tumors. Second, to clarify the molecular context that leads to the specific glycogene expression inside the CC 
441

442

443

444

445 446

447

448

449

450

451

452

453

454

455

456

457

458

459

460

461

462

463

464

465

466

467

468

469

470

471

472

473

474

475

476

477

478

479

480

population. Third, to confirm the putative glycan content changes in each case; and fourth, to know whether a glycogene signature or their encoded proteins can be used as a putative biomarker or a glycome-based classification. In summary, the differences between the AC and SCC types shown here indicate that CC should be deeply characterized to identify subtypes of $\mathrm{CC}$ that allow the development of targeted therapies according to the tumor characteristics.

\section{Acknowledgments}

We thank Dr. Lorena Chávez González, Dr. Simón Guzmán León, Dr. José Luis Santillán Torres, and Dr. Jorge Ramírez for the technical assistance with the microarray determinations and Mr. Gerardo Coello, Mr. Gustavo Corral and Ms. Ana Patricia Gómez for their assistance with the genArise software.

\section{References}

Aco-Tlachi M, Carreño-López R, Martínez-Morales PL, Maycotte P, Aguilar-Lemarroy A, Jave-Suárez LF, Santos-López G, Reyes-Leyva J, Vallejo-Ruiz V. Glycogene expression profiles based on microarray data from cervical carcinoma HeLa cells with partially silenced E6 and E7 HPV oncogenes. Infect Agent Cancer. 2018 Jul 20;13:25. https://doi.org/10.1186/s13027-018-0197-2. PMID: 30038662

Chang IW, Liang PI, Li CC, Wu WJ, Huang CN, Lin VC, Hsu CT, He HL, Wu TF, Hung $\mathrm{CH}$, Li CF. HAS3 underexpression as an indicator of poor prognosis in patients with urothelial carcinoma of the upper urinary tract and urinary bladder. Tumour Biol. 2015 Jul;36(7):5441-50. https://doi.org/10.1007/s13277-015-3210-z. PMID: 25934334.

Chang IW, Liang PI, Li CC, Wu WJ, Huang CN, Lin VC, Hsu CT, He HL, Wu TF, Hung $\mathrm{CH}$, Li CF. HAS3 underexpression as an indicator of poor prognosis in patients with urothelial carcinoma of the upper urinary tract and urinary bladder. Tumour Biol. 2015 Jul;36(7):5441-50. https://doi.org10.1007/s13277-015-3210-z PMID: 25934334.

Chavarro N, Arroyo G, Felipe L, Murichi GW, Pérez I. Cáncer cervicouterino. Anales de Radiología México. 2009; 1:61-79.

Cisneros-Ramírez D, Martínez-Laguna Y, Martínez-Morales P, Aguilar-Lemarroy A, JaveSuárez LF, Santos-López G, Reyes-Leyva J, Vallejo-Ruiz V. Glycogene expression profiles from a HaCaT cell line stably transfected with HPV16 E5 oncogene. Mol Med Rep. 2020;22(6):5444-53. https://doi.org/10.3892/mmr.2020.11630

Clark AT, Guimarães da Costa VM, Bandeira Costa L, Bezerra Cavalcanti CL, De Melo Rêgo MJ, Beltrão EI. Differential expression patterns of N-acetylglucosaminyl transferases and polylactosamines in uterine lesions. Eur J Histochem. 2014 May;58(2):2334. https://doi.org/10.4081/ejh.2014.2334 PMID:24998922

Cordeiro Pedrosa LR, van Cappellen WA, Steurer B, Ciceri D, ten Hagen TL, Eggermont AM, et al. C8-glycosphingolipids preferentially insert into tumor cell membranes and 
481

482

483

484

485

486

487

488

489

490

491

492

493

494

495

496

497

498

499

500

501

502

503

504

505

506

507

508

509

510

511

512

513

514

515

516

517

518

519

520

promote chemotherapeutic drug uptake. Biochim Biophys Acta. 2015 Aug;1848(8):165670. https://doi.org/10.1016/j.bbamem.2015.04.011 PMID:25917957

Csoka AB, Frost GI, Stern R. The six hyaluronidase-like genes in the human and mouse genomes. Matrix Biol. 2001 Dec;20(8):499-508. https://doi.org/10.1016/S0945053X(01)00172-X PMID:11731267

Engelstaedter V, Fluegel B, Kunze S, Mayr D, Friese K, Jeschke U, Bergauer F. Expression of the carbohydrate tumour marker Sialyl Lewis A, Sialyl Lewis X, Lewis Y and Thomsen-Friedenreich antigen in normal squamous epithelium of the uterine cervix, cervical dysplasia and cervical cancer. Histol Histopathol. 2012 Apr;27(4):507-14. https://doi.org/10.14670/HH-27.507 PMID: 22374728

Falantes JF, Trujillo P, Piruat JI, Calderón C, Márquez-Malaver FJ, Martín-Antonio B, Millán A, Gómez M, González J, Martino ML, Montero I, Parody R, Espigado I, UrbanoIspizua A, Pérez-Simón JA. Overexpression of GYS1, MIF, and MYC is associated with adverse outcome and poor response to azacitidine in myelodysplastic syndromes and acute myeloid leukemia. Clin Lymphoma Myeloma Leuk. 2015 Apr;15(4):236-44.

https://doi.org/10.1016/j.clml.2014.10.003 PMID: 25487600

Farkas SA, Milutin-Gašperov N, Grce M, Nilsson TK. Genome-wide DNA methylation assay reveals novel candidate biomarker genes in cervical cancer. Epigenetics. 2013 Nov;8(11):1213-25. https://doi.org/10.4161/epi.26346 PMID:24030264

Gagliardi A, Porter VL, Zong Z, Bowlby R, Titmuss E, Namirembe C, Griner NB, Petrello H, Bowen J, Chan SK, Culibrk L, Darragh TM, Stoler MH, Wright TC, Gesuwan P, Dyer MA, Ma Y, Mungall KL, Jones SJM, Nakisige C, Novik K, Orem J, Origa M, GastierFoster JM, Yarchoan R, Casper C, Mills GB, Rader JS, Ojesina AI, Gerhard DS, Mungall AJ, Marra MA. Analysis of Ugandan cervical carcinomas identifies human papillomavirus clade-specific epigenome and transcriptome landscapes. Nat Genet. 2020 Aug;52(8):80010. https://doi.org/10.1038/s41588-020-0673-7 PMID:32747824

Gamage DG, Hendrickson TL. GPI transamidase and GPI anchored proteins: oncogenes and biomarkers for cancer. Crit Rev Biochem Mol Biol. 2013 Sep-Oct;48(5):446-64. https://doi.org/10.3109/10409238.2013.831024 PMID:23978072

Gao J, Aksoy BA, Dogrusoz U, Dresdner G, Gross B, Sumer SO, Sun Y, Jacobsen A, Sinha R, Larsson E, Cerami E, Sander C, Schultz N. Integrative analysis of complex cancer genomics and clinical profiles using the cBioPortal. Sci Signal. 2013 Apr;6(269):pl1. https://doi.org/10.1126/scisignal.2004088 PMID:23550210

Garnham R, Scott E, Livermore KE, Munkley J. ST6GAL1: A key player in cancer. Oncol Lett. 2019 Aug;18(2):983-989. https://doi.org/10.3892/ol.2019.10458. Epub 2019 Jun 7. PMID: 31423157

Guo Z, Linn JF, Wu G, Anzick SL, Eisenberger CF, Halachmi S, Cohen Y, Fomenkov A, Hoque MO, Okami K, Steiner G, Engles JM, Osada M, Moon C, Ratovitski E, Trent JM, Meltzer PS, Westra WH, Kiemeney LA, Schoenberg MP, Sidransky D, Trink B. CDC91L1 (PIG-U) is a newly discovered oncogene in human bladder cancer [published 
521

522

523

524

525

526

527

528

529

530

531

532

533

534

535

536

537

538

539

540

541

542

543

544

545

546

547

548

549

550

551

552

553

554

555

556

557

558

559

560

correction appears in Nat Med. 2004 Oct;10(10):1139]. Nat Med. 2004 Apr;10(4):374-81. https://doi.org/10.1038/nm1010 PMID:15034568

IARC (World Health Organization International Agency for Research on Cancer.

GLOBOCAN 2020: estimated cancer incidence, mortality, and prevalence worldwide in 2020. [homepage on the internet]; Available from:

http://globocan.iarc.fr/Pages/fact_sheets_cancer.aspx

Itano N, Kimata K. Mammalian hyaluronan synthases. IUBMB Life. 2002 Oct;54(4):195-9. https://doi.org/10.1080/15216540214929 PMID:12512858

Itano N, Sawai T, Yoshida M, Lenas P, Yamada Y, Imagawa M, Shinomura T, Hamaguchi M, Yoshida Y, Ohnuki Y, Miyauchi S, Spicer AP, McDonald JA, Kimata K. Three isoforms of mammalian hyaluronan synthases have distinct enzymatic properties. J Biol Chem. 1999 Aug;274(35):25085-92. https://doi.org/10.1074/jbc.274.35.25085 PMID: 10455188

Jin Y, Kim SC, Kim HJ, Ju W, Kim YH, Kim HJ. Increased sialylation and reduced fucosylation of exfoliated cervical cells are potential markers of carcinogenesis in the cervix. Clin Chem Lab Med. 2016 Nov 1;54(11):1811-1819. https://doi.org/10.1515/cclm2015-1014 PMID: 27092648

Jin Z, Zhang G, Liu Y, He Y, Yang C, Du Y, Gao F. The suppressive role of HYAL1 and HYAL2 in the metastasis of colorectal cancer. J Gastroenterol Hepatol. 2019 Oct;34(10):1766-1776. https://doi.org/10.1111/jgh.14660 PMID: 30972813

Jing J, Zheng S, Han C, Du L, Guo Y, Wang P. Evaluating the value of uPAR of serum and tissue on patients with cervical cancer. J Clin Lab Anal. 2012 Jan;26(1):16-21. https://doi.org/10.1002/jcla.20499 PMID:24833530

Jöhrens K, Lazzerini L, Barinoff J, Sehouli J, Cichon G. Mesothelin as a target for cervical cancer therapy. Arch Gynecol Obstet. 2019 Jan;299(1):211-6.

https://doi.org/10.1007/s00404-018-4933-z PMID:30324544

Jones DT, Lechertier T, Mitter R, Herbert JM, Bicknell R, Jones JL, Li JL, Buffa F, Harris AL, Hodivala-Dilke K. Gene expression analysis in human breast cancer associated blood vessels. PLoS One. 2012;7(10):e44294. https://doi.org/10.1371/journal.pone.0044294. PMID: 23056178

Kaneiwa T, Miyazaki A, Kogawa R, Mizumoto S, Sugahara K, Yamada S. Identification of amino acid residues required for the substrate specificity of human and mouse chondroitin sulfate hydrolase (conventional hyaluronidase-4). J Biol Chem. 2012 Dec 7;287(50):42119-28. https://doi.org10.1074/jbc.M112.360693 PMID: 23086929

Kannagi R, Yin J, Miyazaki K, Izawa M. Current relevance of incomplete synthesis and neosynthesis for cancer-associated alteration of carbohydrate determinants - hakomori's concepts revisited. Biochim Biophys Acta. 2008 Mar;1780(3):525-31. https://doi.org/10.1016/j.bbagen.2007.10.007 PMID:17980710

Kondoh N, Wakatsuki T, Ryo A, Hada A, Aihara T, Horiuchi S, Goseki N, Matsubara O, Takenaka K, Shichita M, Tanaka K, Shuda M, Yamamoto M. Identification and 
561

characterization of genes associated with human hepatocellular carcinogenesis. Cancer Res. 1999 Oct 1;59(19):4990-6. PMID: 10519413

Kundu S, Xiong A, Spyrou A, Wicher G, Marinescu VD, Edqvist PD, Zhang L, Essand M, Dimberg A, Smits A, Ilan N, Vlodavsky I, Li JP, Forsberg-Nilsson K. Heparanase Promotes Glioma Progression and Is Inversely Correlated with Patient Survival. Mol Cancer Res. 2016 Dec;14(12):1243-1253. https://doi.org/10.1158/1541-7786.MCR-160223 PMID: 27565180

Le PH, Kuo CJ, Hsieh YC, Chen TH, Lin CL, Yeh CT, Liang KH. Ages of hepatocellular carcinoma occurrence and life expectancy are associated with a UGT2B28 genomic variation. BMC Cancer. 2019 Dec 5;19(1):1190. https://doi.org/10.1186/s12885-019-64093. PMID: 31805979

Li X, Lan Y, He Y, Liu Y, Luo H, Yu H, Song N, Ren S, Liu T, Hao C, Guo Y, Zhang L. Heparan Sulfate and Chondroitin Sulfate Glycosaminoglycans Are Targeted by Bleomycin in Cancer Cells. Cell Physiol Biochem. 2017;43(3):1220-34.

https://doi.org/10.1159/000481763 PMID:28982096

Liao YM, Wang YH, Hung JT, Lin YJ, Huang YL, Liao GS, Hsu YL, Wu JC, Yu AL. High B3GALT5 expression confers poor clinical outcome and contributes to tumor progression and metastasis in breast cancer. Breast Cancer Res. 2021 Jan 7;23(1):5. doi: 10.1186/s13058-020-01381-9. PMID: 33413566

Libisch MG, Casás M, Chiribao M, Moreno P, Cayota A, Osinaga E, Oppezzo P, Robello C. GALNT11 as a new molecular marker in chronic lymphocytic leukemia. Gene. 2014 Jan 1;533(1):270-9. https://doi.org/10.1016/j.gene.2013.09.052 PMID: 24076351

Lin HW, Chiang YC, Sun NY, Chen YL, Chang CF, Tai YJ, Chen CA, Cheng WF. CHI3L1 results in poor outcome of ovarian cancer by promoting properties of stem-like cells. Endocr Relat Cancer. 2019 Jan 1;26(1):73-88. https://doi.org/10.1530/ERC-18-0300 PMID: 30121622.

Lin MC, Chien PH, Wu HY, Chen ST, Juan HF, Lou PJ, Huang MC. C1GALT1 predicts poor prognosis and is a potential therapeutic target in head and neck cancer. Oncogene. 2018 Oct;37(43):5780-93. https://doi.org/10.1038/s41388-018-0375-0 PMID:29930379

Liu C, Ding L, Bai L, Chen X, Kang H, Hou L, Wang J. Folate receptor alpha is associated with cervical carcinogenesis and regulates cervical cancer cells growth by activating ERK1/2/c-Fos/c-Jun. Biochem Biophys Res Commun. 2017 Sep;491(4):1083-91. https://doi.org/10.1016/j.bbrc.2017.08.015 PMID:28782518

Liu G, Tang H, Li C, Zhen H, Zhang Z, Sha Y. Prognostic gene biomarker identification in liver cancer by data mining. Am J Transl Res. 2021 May 15;13(5):4603-4613. PMID: 34150040

Liu X, Wu J, Zhang D, Bing Z, Tian J, Ni M, Zhang X, Meng Z, Liu S. Identification of Potential Key Genes Associated With the Pathogenesis and Prognosis of Gastric Cancer Based on Integrated Bioinformatics Analysis. Front Genet. 2018 Jul 17;9:265. https://doi.org10.3389/fgene.2018.00265. PMID: 30065754 
601

602

603

604

605

606

607

608

609

610

611

612

613

614

615

616

617

618

619

620

621

622

623

624

625

626

627

628

629

630

631

632

633

634

635

636

637

638
Liu YY, Gupta V, Patwardhan GA, Bhinge K, Zhao Y, Bao J, Mehendale H, Cabot MC, Li YT, Jazwinski SM. Glucosylceramide synthase upregulates MDR1 expression in the regulation of cancer drug resistance through $\mathrm{cSrc}$ and $\beta$-catenin signaling. Mol Cancer. 2010 Jun;9(1):145. https://doi.org/10.1186/1476-4598-9-145 PMID:20540746

López-Morales D, Reyes-Leyva J, Santos-López G, Zenteno E, Vallejo-Ruiz V. Increased expression of sialic acid in cervical biopsies with squamous intraepithelial lesions. Diagn Pathol. 2010 Nov 22;5:74. https://doi.org/10.1186/1746-1596-5-74 PMID: 21092209

López-Morales D, Velázquez-Márquez N, Valenzuela O, Santos-López G, Reyes-Leyva J, Vallejo-Ruiz, V. Enhanced sialyltransferases transcription in cervical intraepithelial neoplasia. Investigación clínica. 2009; 50(1): 45-53.

Maierthaler M, Kriegsmann M, Peng C, Jauch S, Szabo A, Wallwiener M, Rom J, Sohn C, Schneeweiss A, Sinn HP, Yang R, Burwinkel B. S100P and HYAL2 as prognostic markers for patients with triple-negative breast cancer. Exp Mol Pathol. 2015 Aug;99(1):180-7. https://doi.org/10.1016/j.yexmp.2015.06.010 PMID: 26112095

Munkley J, Elliott DJ. Hallmarks of glycosylation in cancer. Oncotarget. 2016 Jun;7(23):35478-89. https://doi.org/10.18632/oncotarget.8155 PMID:27007155

Ngernyuang N, Shao R, Suwannarurk K, Limpaiboon T. Chitinase 3 like 1 (CHI3L1) promotes vasculogenic mimicry formation in cervical cancer. Pathology. 2018 Apr;50(3):293-297. https://doi.org/10.1016/j.pathol.2017.09.015 PMID: 29452694.

Numa F, Tsunaga N, Michioka T, Nawata S, Ogata H, Kato H. Tissue expression of Sialyl Tn antigen in gynecologic tumors. J Obstet Gynaecol. 1995 Aug;21(4):385-9. https://doi: 10.1111/j.1447-0756.1995.tb01027.x PMID: 8775909

Nykopp TK, Rilla K, Tammi MI, Tammi RH, Sironen R, Hämäläinen K, Kosma VM, Heinonen S, Anttila M. Hyaluronan synthases (HAS1-3) and hyaluronidases (HYAL1-2) in the accumulation of hyaluronan in endometrioid endometrial carcinoma. BMC Cancer. 2010 Sep 27;10:512. https://doi.org/10.1186/1471-2407-10-512. PMID: 20875124

Oliveira-Ferrer L, Heßling A, Trillsch F, Mahner S, Milde-Langosch K. Prognostic impact of chondroitin-4-sulfotransferase CHST11 in ovarian cancer. Tumour Biol. 2015 Nov;36(11):9023-30. https://doi.org/10.1007/s13277-015-3652-3 PMID: 26084610

Passi A, Vigetti D, Buraschi S, Iozzo RV. Dissecting the role of hyaluronan synthases in the tumor microenvironment. FEBS J. 2019 Aug;286(15):2937-49.

https://doi.org/10.1111/febs.14847 PMID:30974514

Pinho SS, Oliveira P, Cabral J, Carvalho S, Huntsman D, Gärtner F, Seruca R, Reis CA, Oliveira C. Loss and recovery of Mgat3 and GnT-III Mediated E-cadherin N-glycosylation is a mechanism involved in epithelial-mesenchymal-epithelial transitions. PLoS One. 2012;7(3):e33191. https://doi.org/10.1371/journal.pone.0033191 PMID:22427986

Pinho SS, Reis CA. Glycosylation in cancer: mechanisms and clinical implications. Nat Rev Cancer. 2015 Sep;15(9):540-55. https://doi.org/10.1038/nrc3982 PMID:26289314 
639

640

641

642

643

644

645

646

647

648

649

650

651

652

653

654

655

656

657

658

659

660

661

662

663

664

665

666

667

668

669

670

671

672

673

674

675

676

677

678

Price ZK, Lokman NA, Ricciardelli C. Differing Roles of Hyaluronan Molecular Weight on Cancer Cell Behavior and Chemotherapy Resistance. Cancers (Basel). 2018 Dec;10(12):482. https://doi.org/10.3390/cancers10120482 PMID:30513961

Roy A, Chakraborty S. Detection of cancer cervix by estimation of sialic acid. J Indian Med Assoc. 2005 Nov;103(11):589-90. PMID: 16570760

Sachiko A. and Kiyohiko A. Databases of glycogenes (GGDB and FlyGlycoDB). Glycoforum 2019; 22 (3). DOI:10.32285/glycoforum.22A7. Retrieved from https://glycoforum.gr.jp/article/22A7.html

Salustiano EJ, da Costa KM, Freire-de-Lima L, Mendonça-Previato L, Previato JO. Inhibition of glycosphingolipid biosynthesis reverts multidrug resistance by differentially modulating ABC transporters in chronic myeloid leukemias. J Biol Chem. 2020 May;295(19):6457-71. https://doi.org/10.1074/jbc.RA120.013090 PMID:32229586

Sano T, Ueki M. Stromal reactions to squamous cell carcinoma of the cervix. Am J Obstet Gynecol. 1987 Apr;156(4):906-10. https://doi.org/10.1016/0002-9378(87)90350-4 PMID:3034058

Sayagués JM, Corchete LA, Gutiérrez ML, Sarasquete ME, Del Mar Abad M, Bengoechea O, Fermiñán E, Anduaga MF, Del Carmen S, Iglesias M, Esteban C, Angoso M, Alcazar JA, García J, Orfao A, Muñoz-Bellvis L. Genomic characterization of liver metastases from colorectal cancer patients. Oncotarget. 2016 Nov 8;7(45):72908-72922. https://doi.org/10.18632/oncotarget.12140. PMID: 27662660

Schjoldager KT, Narimatsu Y, Joshi HJ, Clausen H. Global view of human protein glycosylation pathways and functions. Nat Rev Mol Cell Biol. 2020 Oct. https://doi.org/10.1038/s41580-020-00294-x PMID:33087899

Srinivasan R. Cervical cancer genomics: an initial step towards personalized approach to therapy. EBioMedicine. 2019 May;43:11-12. https://doi.org/10.1016/j.ebiom.2019.04.025 PMID: 31005518

Sun Y, Yang X, Liu M, Tang H. B4GALT3 up-regulation by miR-27a contributes to the oncogenic activity in human cervical cancer cells. Cancer Lett. 2016 Jun;375(2):284-92. https://doi.org/10.1016/j.canlet.2016.03.016 PMID:26987623

Szklarczyk D, Gable AL, Lyon D, Junge A, Wyder S, Huerta-Cepas J, Simonovic M, Doncheva NT, Morris JH, Bork P, Jensen LJ, Mering CV. STRING v11: protein-protein association networks with increased coverage, supporting functional discovery in genomewide experimental datasets. Nucleic Acids Res. 2019 Jan;47 D1:D607-13. https://doi.org/10.1093/nar/gky1131 PMID:30476243

Tang D, Piao Y, Zhao S, Mu X, Li S, Ma W, Song Y, Wang J, Zhao W, Zhang Q. Expression and correlation of matrix metalloproteinase- 9 and heparanase in patients with breast cancer. Med Oncol. 2014 Jul;31(7):26. https://doi.org/10.1007/s12032-014-0026-4PMID: 24861922

Tavianatou A, Piperigkou Z, Barbera C, Beninatto R, Masola V, Caon I, Onisto M, Franchi M, Galesso D, Karamanos NK. Molecular size-dependent specificity of hyaluronan on 
679

680

681

682

683

684

685

686

687

688

689

690

691

692

693

694

695

696

697

698

699

700

701

702

703

704

705

706

707

708

709

710

711

712

713

714

715

716

717

functional properties,morphology and matrix composition of mammary cancer cells.

Matrix Biol. 2019a; 3:1-24. https://doi.org/10.1016/j.mbplus.2019.100008. PMID: 33543007

Tavianatou AG, Caon I, Franchi M, Piperigkou Z, Galesso D, Karamanos NK. Hyaluronan: molecular size-dependent signaling and biological functions in inflammation and cancer. FEBS J. 2019b Aug;286(15):2883-908. https://doi.org/10.1111/febs.14777 PMID:30724463

TCGA (The Cancer Genome Atlas Research Network)., Albert Einstein College of Medicine., Burk, R. et al. Integrated genomic and molecular characterization of cervical cancer. Nature. 2017 March 543, 378-384 https://doi.org/10.1038/nature21386. PMID: 28112728

Teye EK, Sido A, Xin P, Finnberg NK, Gokare P, Kawasawa YI, Salzberg AC, Shimko S, Bayerl M, Ehmann WC, Claxton DF, Rybka WB, Drabick JJ, Wang HG, Abraham T, ElDeiry WS, Brodsky RA, J Hohl R, Pu JJ. PIGN gene expression aberration is associated with genomic instability and leukemic progression in acute myeloid leukemia with myelodysplastic features. Oncotarget. 2017 May 2;8(18):29887-29905.

https://doi.org10.18632/oncotarget.15136. PMID: 28187452

van der Heijden AG, Mengual L, Lozano JJ, Ingelmo-Torres M, Ribal MJ, Fernández PL, Oosterwijk E, Schalken JA, Alcaraz A, Witjes JA. A five-gene expression signature to predict progression in T1G3 bladder cancer. Eur J Cancer. 2016 Sep;64:127-36. https://doi.org/10.1016/j.ejca.2016.06.003 PMID: 27414486

Velázquez-Márquez N, Santos-López G, Jiménez-Aranda L, Reyes-Leyva J, Vallejo-Ruiz V. Sialyl Lewis x expression in cervical scrapes of premalignant lesions. J Biosci. 2012 Dec;37(6):999-1004. https://doi.org/10.1007/s12038-012-9261-z PMID: 23151790 Venkitachalam S, Revoredo L, Varadan V, Fecteau RE, Ravi L, Lutterbaugh J, Oosterwijk E, Schalken JA, Alcaraz A, Witjes JA. Biochemical and functional characterization of glycosylation-associated mutational landscapes in colon cancer. Sci Rep. 2016 Mar 23;6:23642. https://doi.org/10.1038/srep23642 PMID: 27004849

Vojta A, Samaržija I, Bočkor L, Zoldoš V. Glyco-genes change expression in cancer through aberrant methylation. Biochim Biophys Acta. 2016 Aug;1860(8):1776-85.https:// doi: 10.1016/j.bbagen.2016.01.002 PMID: 26794090

Wang F, Grigorieva EV, Li J, Senchenko VN, Pavlova TV, Anedchenko EA, Kudryavtseva AV, Tsimanis A, Angeloni D, Lerman MI, Kashuba VI, Klein G, Zabarovsky ER. HYAL1 and HYAL2 inhibit tumour growth in vivo but not in vitro. PLoS One. 2008 Aug;3(8):e3031. https://doi.org/10.1371/journal.pone.0003031 PMID:18725949

Wang PH, Lee WL, Lee YR, Juang CM, Chen YJ, Chao HT, Tsai YC, Yuan CC. Enhanced expression of alpha 2,6-sialyltransferase ST6Gal I in cervical squamous cell carcinoma. Gynecol Oncol. 2003 Jun;89(3):395-401. https://doi.org/10.1016/s0090-8258(03)00127-6 PMID: 12798701 
718

719

720

721

722

723

724

725

726

727

728

729

730

731

732

733

734

735

736

737

738

739

740

741

742

743

744

745

746

747

748

749

Wang PH, Li YF, Juang CM, Lee YR, Chao HT, Ng HT, Tsai YC, Yuan CC. Expression of sialyltransferase family members in cervix squamous cell carcinoma correlates with lymph node metastasis. Gynecol Oncol. 2002 Jul;86(1):45-52.

https://doi.org/10.1006/gyno.2002.6714 PMID: 12079299

Wang PH, Li YF, Juang CM, Lee YR, Chao HT, Tsai YC, Yuan CC. Altered mRNA expression of sialyltransferase in squamous cell carcinomas of the cervix. Gynecol Oncol. 2001 Oct;83(1):121-7. https://doi.org/10.1006/gyno.2001.6358 PMID: 11585423

Welinder C, Pawłowski K, Szasz AM, Yakovleva M, Sugihara Y, Malm J, Jönsson G, Ingvar C, Lundgren L, Baldetorp B, Olsson H, Rezeli M, Laurell T, Wieslander E, Marko-Varga G. Correlation of histopathologic characteristics to protein expression and function in malignant melanoma. PLoS One. 2017 Apr 26;12(4):e0176167. https://doi.org/10.1371/journal.pone.0176167. PMID: 28445515

Yang Z, Chen S, Luan X, Li Y, Liu M, Li X, Liu T, Tang H. MicroRNA-214 is aberrantly expressed in cervical cancers and inhibits the growth of HeLa cells. IUBMB Life. 2009 Nov;61(11):1075-82. https://doi.org/10.1002/iub.252 PMID:19859982

Yip GW, Smollich M, Götte M. Therapeutic value of glycosaminoglycans in cancer. Mol Cancer Ther. 2006 Sep;5(9):2139-48. https://doi.org/10.1158/1535-7163.MCT-06-0082 PMID: 16985046

Yu Y, Kou D, Liu B, Huang Y, Li S, Qi Y, Guo Y, Huang T, Qi X, Jia L. LncRNA MEG3 contributes to drug resistance in acute myeloid leukemia by positively regulating ALG9 through sponging miR-155. Int J Lab Hematol. 2020 Aug;42(4):464-472. doi: 10.1111/ijlh.13225. PMID: 32359033.

Zhang W, Chan H, Wei L, Pan Z, Zhang J, Li L. Overexpression of heparanase in ovarian cancer and its clinical significance. Oncol Rep. 2013 Nov;30(5):2279-87. https://doi.org/10.3892/or.2013.2701 PMID: 23982701

Zhao P, Nairn AV, Hester S, Moremen KW, O'Regan RM, Oprea G, Wells L, Pierce M, Abbott KL. Proteomic Identification of Glycosylphosphatidylinositol Anchor-dependent Membrane Proteins Elevated in Breast Carcinoma. Biol Chem. 2012 Jul;287(30):2523040. https://doi.org/10.1074/jbc.M112.339465 PMID: 22654114

Zhuo D, Li X, Guan F. Biological Roles of Aberrantly Expressed Glycosphingolipids and Related Enzymes in Human Cancer Development and Progression. Front Physiol. 2018 May; 9:466. https://doi.org/10.3389/fphys.2018.00466 PMID:29773994 


\section{Figure 1}

STRING protein-protein interaction network among the altered glycogenes in cervical cancer in comparison with a normal cervix.

A) Interaction among the upregulated glycogenes shows two predicted cellular processes: the glycosylphosphatidylinositol (GPI) biosynthesis process (in red) and an immune system response process (in blue). B) Interaction among the downregulated glycogenes shows the predicted network between HYAL2 and HAS3 in the hyaluronan metabolic process (in yellow). C) Interaction among the upregulated glycogenes with five predicted interactors shows that the glycogenes PIGC and PIGN interact with more glycogenes of the GPI biosynthesis process (in red), while CHI3L1 and HEXB are predicted to interact with FUCA2 in the neutrophil degradation process (in green). D) Interaction among the downregulated glycogenes and their respective predicted interactors shows four networks: HYAL2 and HAS3 along with CD44 participate in the hyaluronan metabolic process (in yellow); also, HAS3 is predicted to interact with UGP2 in pentose and glucuronate interconversions (in purple), glycogen biosynthetic process (in brown) and starch and sucrose metabolism (in gold). In addition, the glycogene CHST12 was predicted to interact with CHST3 and CHST7 in the chondroitin sulfate/dermatan sulfate biosynthesis process (in violet) 
A

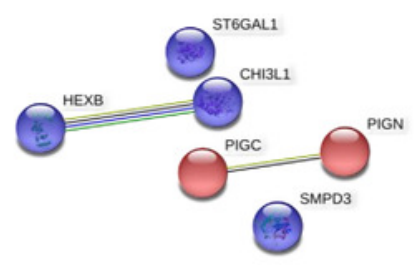

C

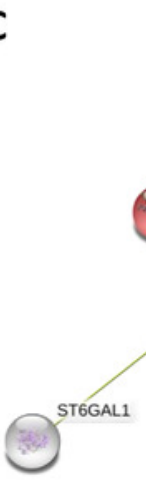

B

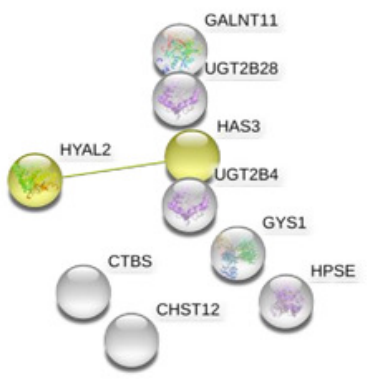

GPI-anchor biosynthesis

Immune system response

Neutrophil degranulation

Hyaluronan metabolic process

Proteoglycans in cancer

Chondroitin sulfate/dermatan sulfate biosynthesis

Pentose and glucuronate interconversions

Starch and sucrose metabolism

Glycogen biosynthetic process

D
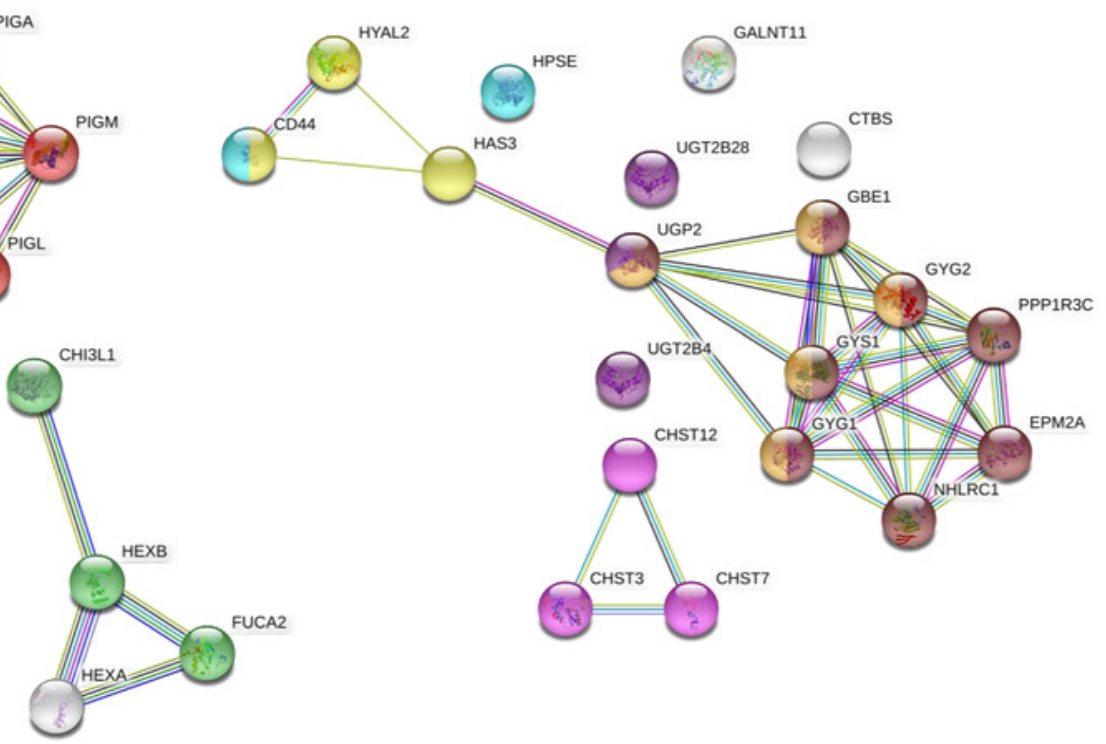


\section{Figure 2}

Glycogene expression comparsion between adenocarcinoma and squamous carcinoma.

Glycogene expression comparsion between adenocarcinoma and squamous carcinoma. A) Heat map of glycogene expression in squamous carcinoma and adenocarcinoma and clusters of glycogenes. B) KEGG pathway enrichment analysis of glycogenes in AC-A, AC-B (C) and, AC-C (D). Red color indicates high expresión and blue color low expression. GSLs:

glycosphincolipids; GAGs: glycosaminoglycans; GPI: glycosylphosphatidylinositol 


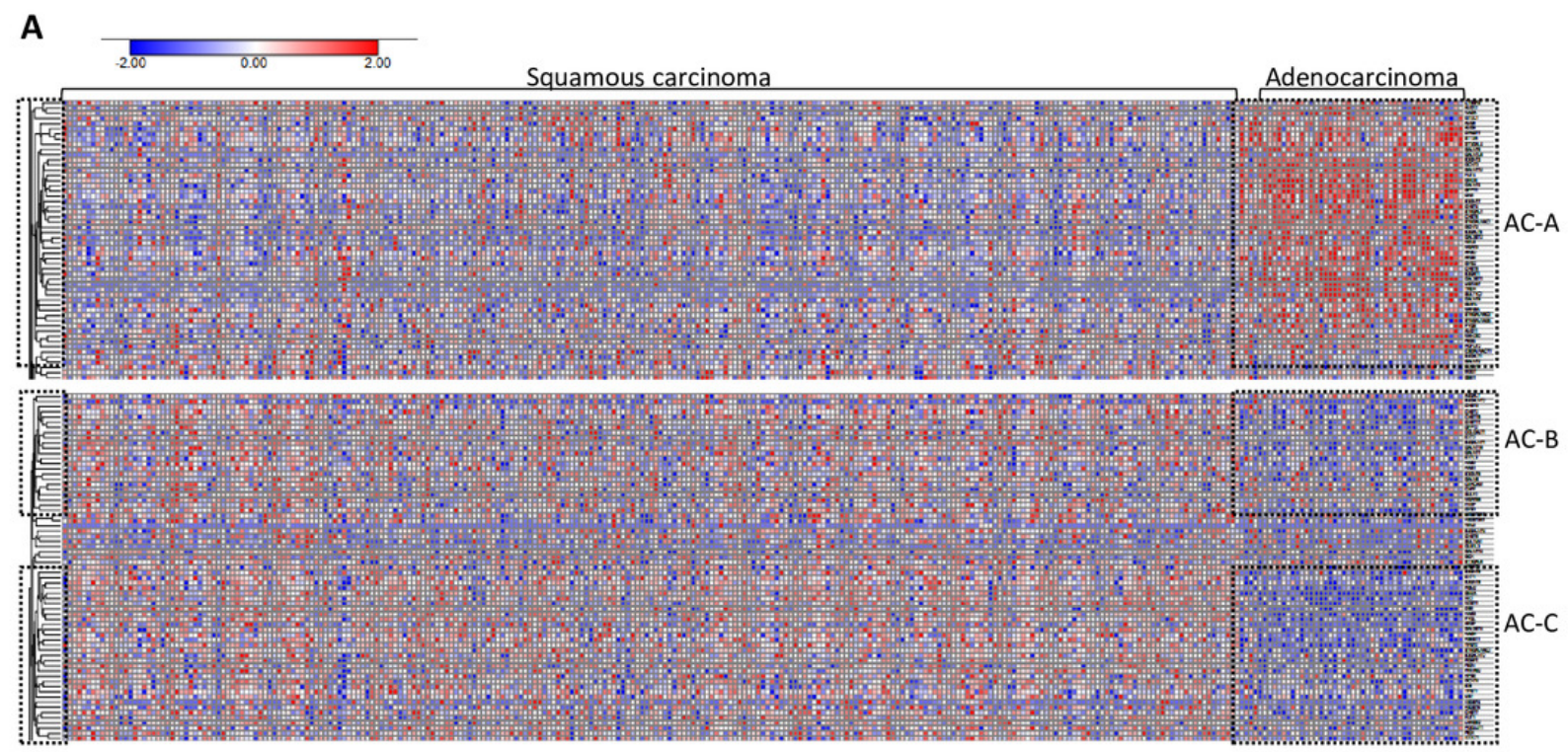

B

KEGG enrichment of glycogenes in AC-A

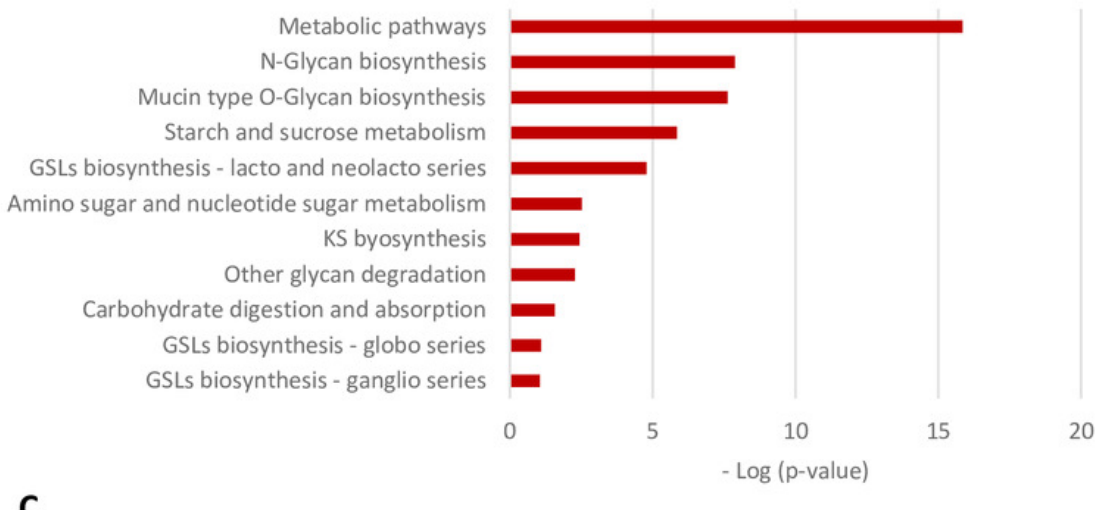

KEGG enrichment of glycogenes AC-B

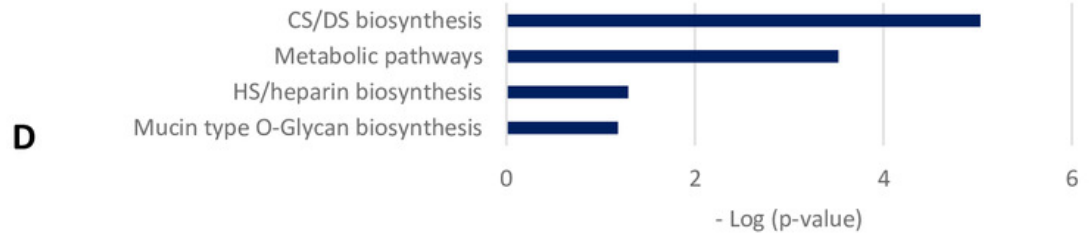

KEGG enrichment of glycogenes in AC-C

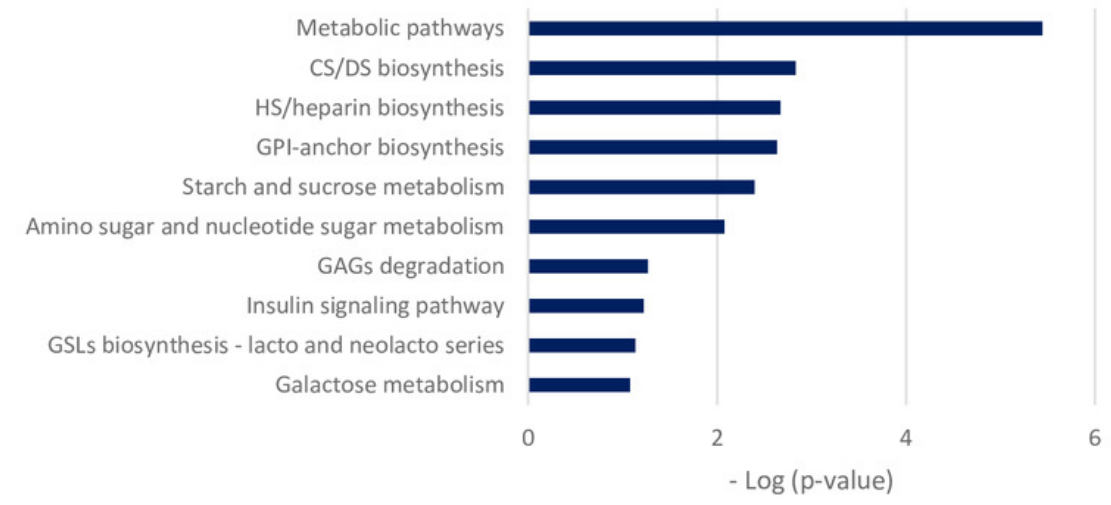




\section{Figure 3}

Screening of the glycogene expression pattern in cervical squamous carcinoma.

A) Heat map of glycogene expression and unsupervised hierarchal analysis showing two different clusters of patient samples, SCC-1 and SCC-2, that display certain clusters of glycogenes (SCC-1A and SCC-1B, and SCC-2A, respectively). B) KEGG enrichment analysis of the cluster of glycogenes with low expression in SCC-2A. C) KEGG enrichment analysis of glycogenes with high expression (SCC-1A) and low expression (SCC-1B). CS: chondroitin sulfate; DS dermatan sulfate; HS: heparan sulfate; GSLs: glycosphingolipids; GAGs: glycosaminoglycans; GPI: glycosylphosphatidylinositol. Red indicates high expression, while blue indicates low expression. 


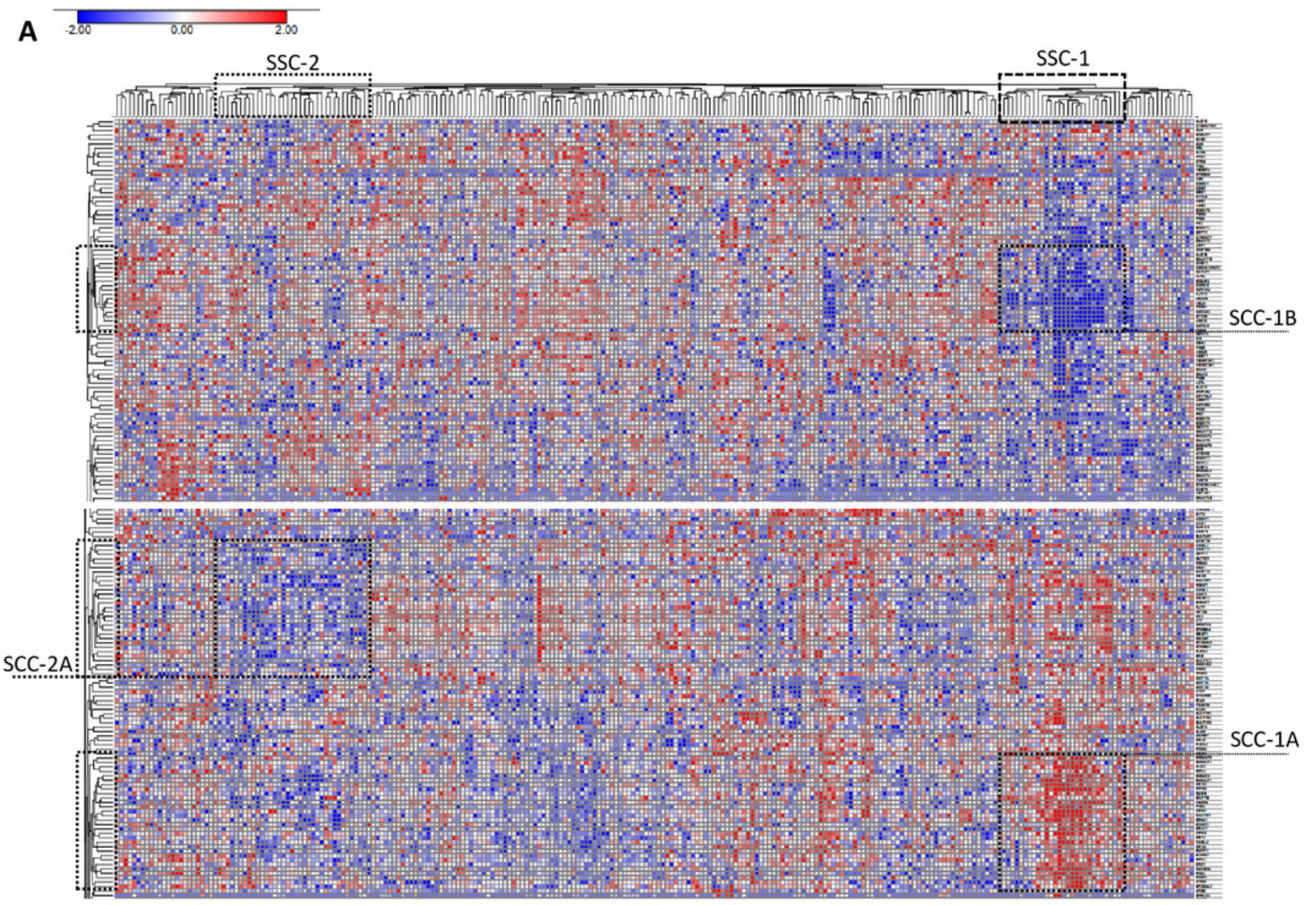

B

KEGG enrichment of glycogenes of SCC-2A

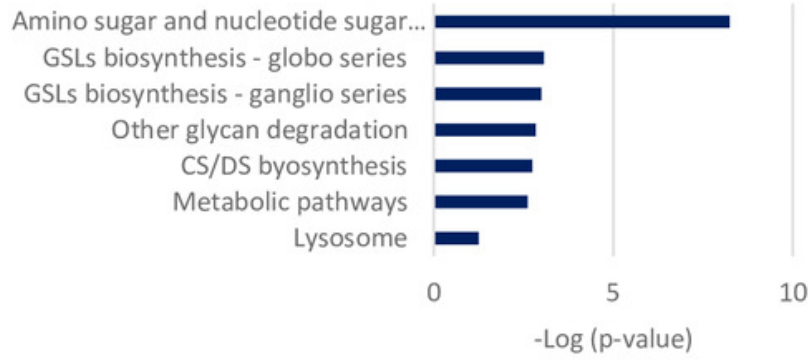

C

KEGG enrichment of glycogenes of SCC-1A and SCC-1B

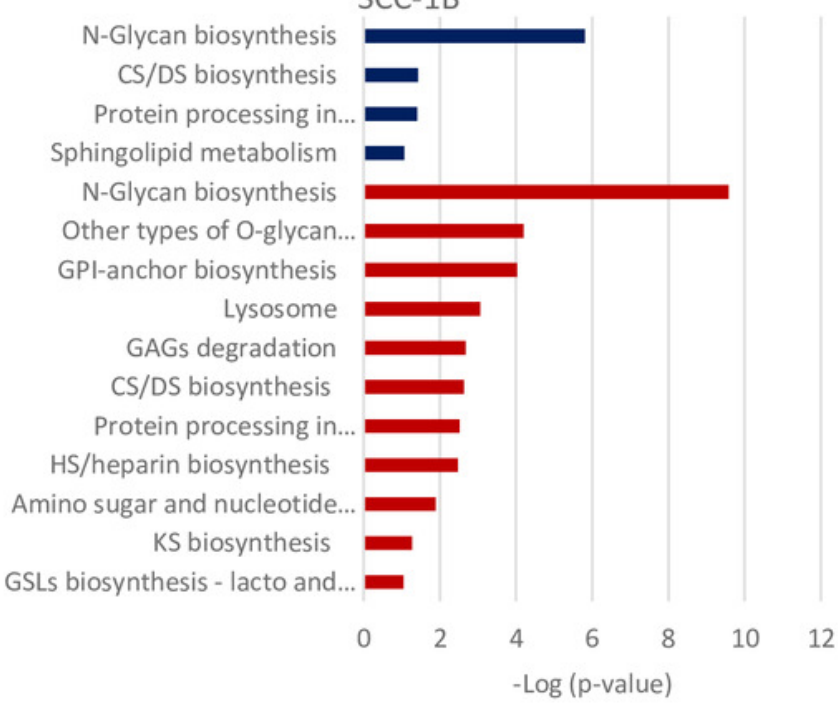




\section{Figure 4}

Four clusters of cervical squamous carcinoma samples displayed a specific glycogene expression pattern.
A) Heat map of glycogene expression of squamous carcinoma samples that contain complete clinical information. B) KEGG enrichment analysis of glycogenes in SCC-3 and SCC-5 (C). D) KEGG enrichment of glycogenes in SCC-4 with low expression in blue color and high expression in red color. E) KEGG enrichment analysis in SCC-6. SCC: squamous carcinoma cluster; HS: heparan sulfate; GSLs: glycosphingolipids; CS: chondroitin sulfate; DS: dermatan sulfate; GPI: glycosylphosphatidylinositol; GAGs: glycosaminoglycans. Blue indicates low expression, and red indicates high expression. 
A

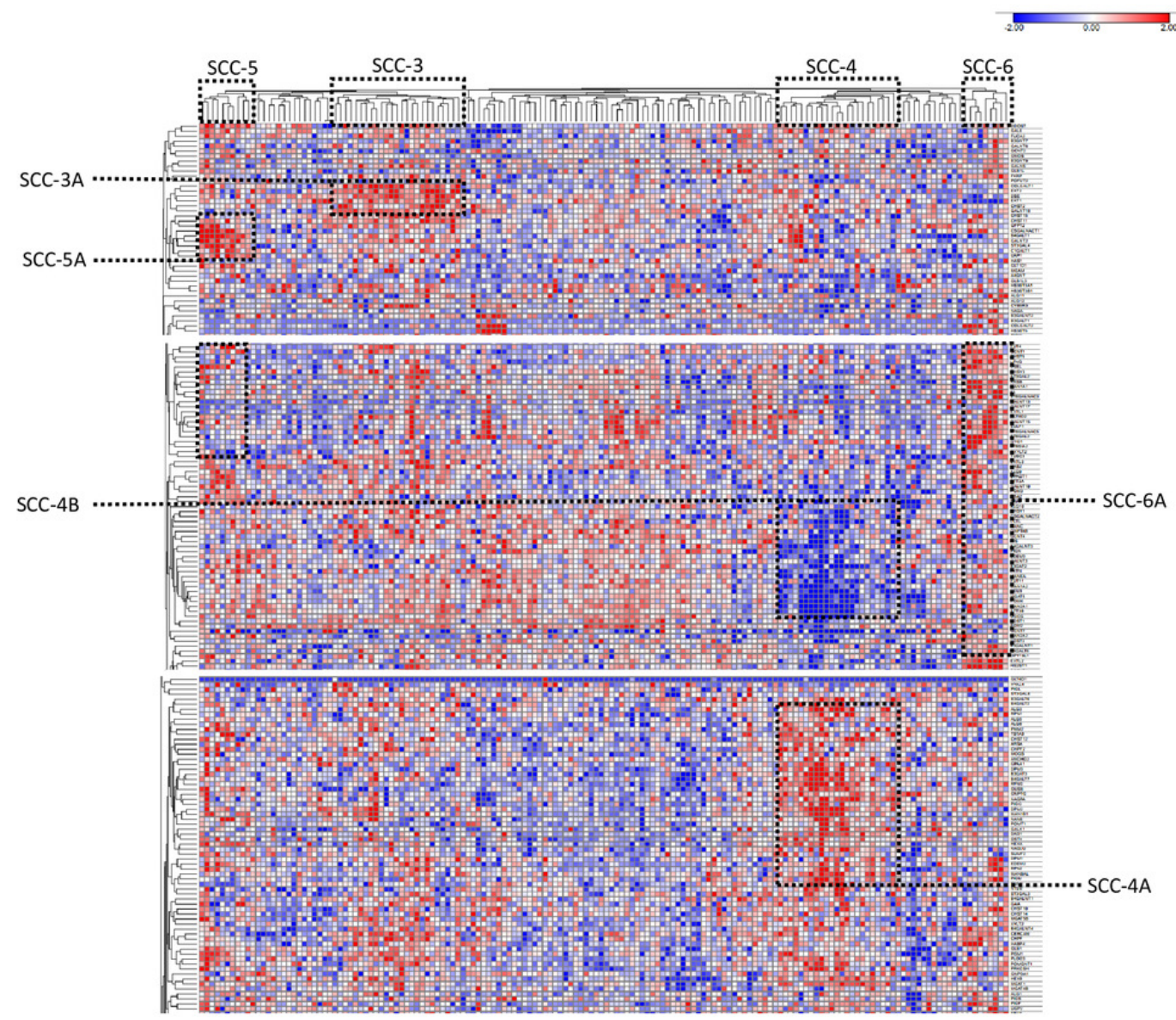

B

KEGG enrichment of glycogenes in SCC-3

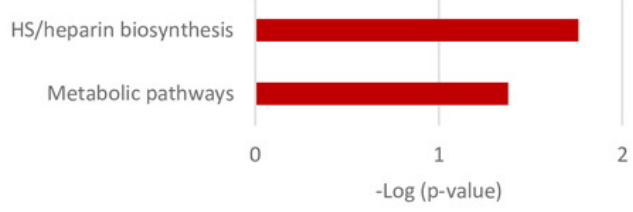

D

KEGG enrichment of glycogenes in SCC-4A and SCC-4B

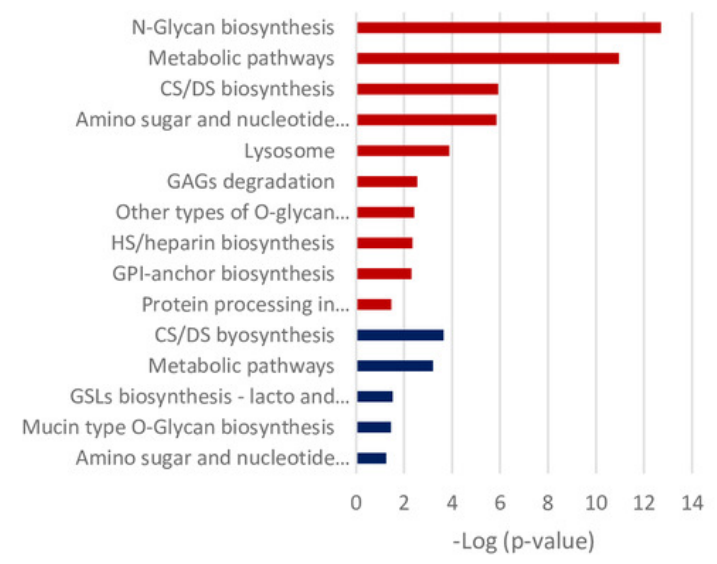

C

KEGG enrichment of glycogenes in SCC-5

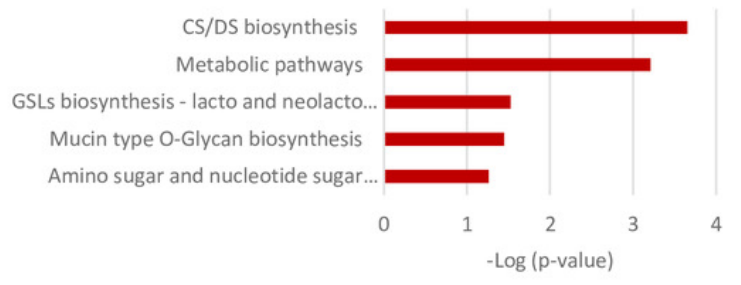

E

KEGG enrichment of glycogenes in SCC-6

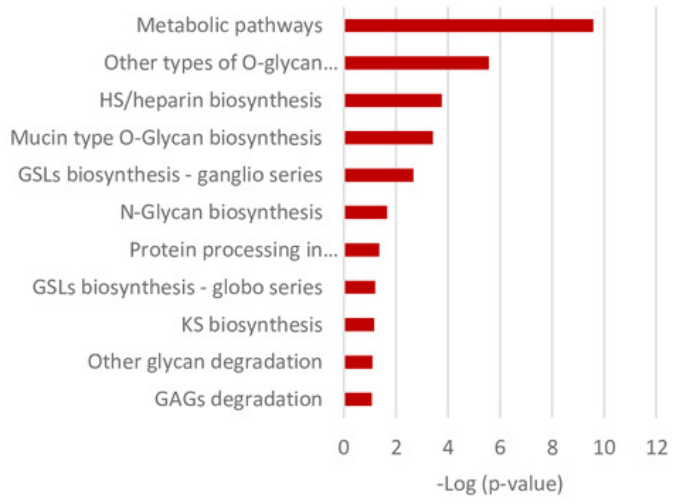




\section{Figure 5}

Altered glycogenes in adenocarcinoma and types of squamous cancer and their respective implicated glycosylation pathways.

Cells in red indicate that all glycogenes display high expression compared to the rest of the cervical cancer samples, while cells in blue indicate that all glycogenes show low expression. Cells in yellow indicate that some of the glycogenes implicated in the same glycosylation pathway display high expression and others low expression; the glycogenes with high expression are located in the first part of the cell, while glycogenes with low expression are located in the second part and separated by a hyphen.

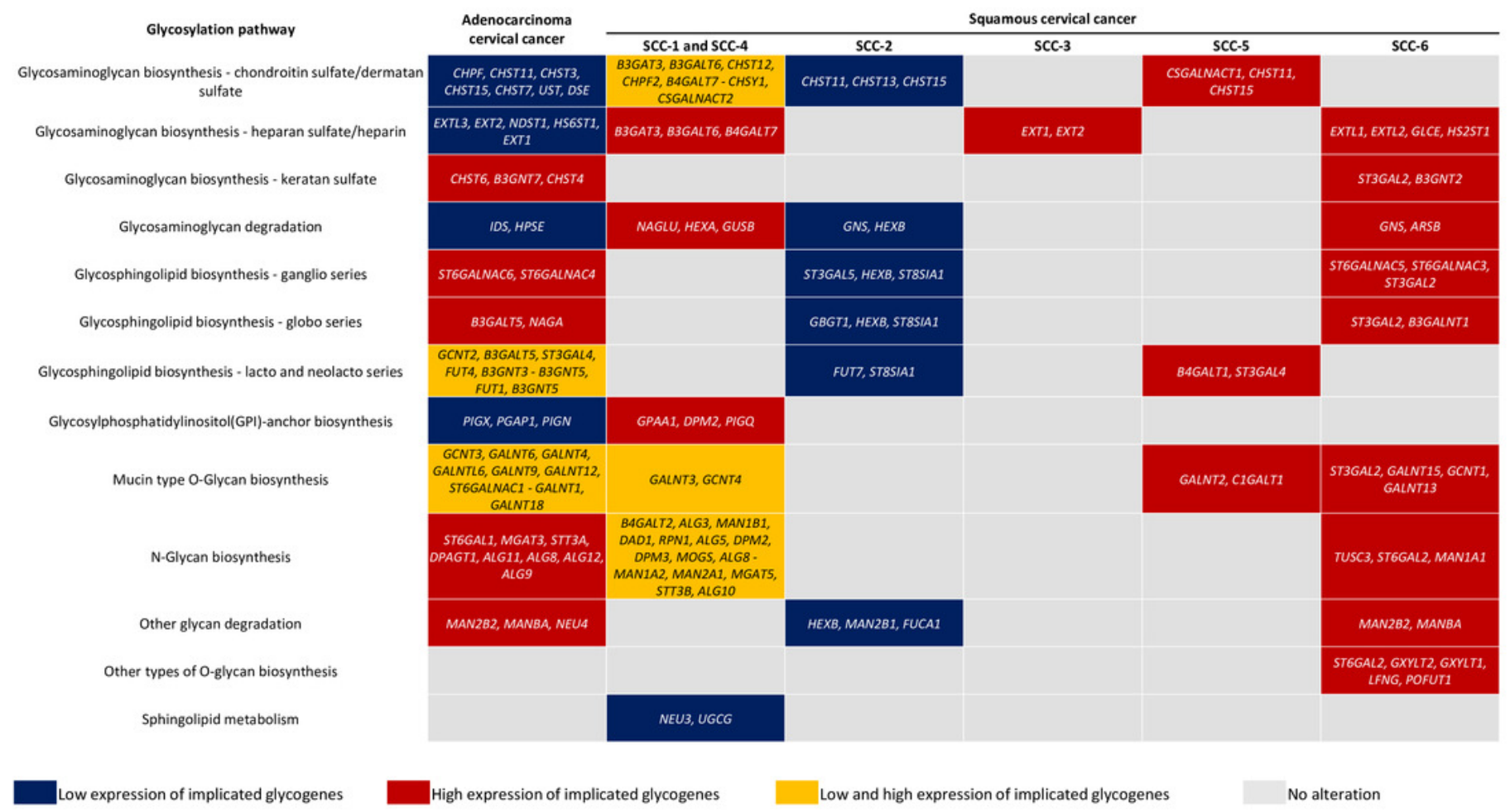




\section{Table $\mathbf{1}$ (on next page)}

Glycogenes increased in cervical cancer patients and aberrantly expressed in several types of cancers. 


\section{Table 1. Glycogenes that are increased in cervical cancer patients and their aberrant 2 expression in several types of cancers.}

\begin{tabular}{|c|c|c|}
\hline Glycogene & Enzyme function & Reports in cancer patients \\
\hline$P I G C$ & $\begin{array}{l}\text { Encodes for the phosphatidylinositol N- } \\
\text { acetylglucosaminyltransferase subunit } \mathrm{C} \text { that is } \\
\text { involved in the glycosilphosphatidylinol anchor } \\
\text { biosynthesis }\end{array}$ & No reported as altered in cancer patients \\
\hline$P I G N$ & $\begin{array}{l}\text { Encodes for GPI ethanolamine phosphate } \\
\text { transferase } 1 \text { that is involved in the } \\
\text { glycosilphosphatidylinol anchor biosynthesis }\end{array}$ & $\begin{array}{l}\text { Expression aberration is associated with progression in acute } \\
\text { myeloid leukemia (Teye et al 2017) }\end{array}$ \\
\hline SMPD3 & $\begin{array}{l}\text { Sphingomyelin phosphodiesterase } 3 \text { that catalyzes } \\
\text { the hydrolysis of sphingomyelin to form ceramide } \\
\text { and phosphocholine }\end{array}$ & Associated with good prognosis in gastric cancer (Liu et al 2018) \\
\hline CHI3L1 & $\begin{array}{l}\text { Chitinase-3-like protein } 1 \text {. Although it belongs to } \\
\text { the glycosyl hydrolase } 18 \text { family, Leu-140 is } \\
\text { present instead of the conserved Glu which is an } \\
\text { active site residue. Therefore, this protein lacks } \\
\text { chitinase activity. }\end{array}$ & $\begin{array}{l}\text { Expression associated with vasculogenic mimicry in cervical } \\
\text { cancer patients (Ngernyuang et al 2018) and its high expression is } \\
\text { associated with poor outcome and chemoresistance in ovarian } \\
\text { cancer patients (Lin et al 2019) }\end{array}$ \\
\hline$H E X B$ & $\begin{array}{l}\text { Beta-hexosaminidase subunit beta involved in } \\
\text { hydrolysis of gangliosides GM2 to GM3 }\end{array}$ & $\begin{array}{l}\text { Upregulation in invasive ductal carcinoma-associated blood } \\
\text { vessels (Jones et al 2012) and poor survival of melanoma patients } \\
\text { (Welinder et al 2017) }\end{array}$ \\
\hline ST6GAL1 & $\begin{array}{l}\text { Beta-galactoside alpha-2,6-sialyltransferase } 1 \text { that } \\
\text { transfers sialic acid from CMP-sialic acid to } \\
\text { galactose-containing acceptor substrates }\end{array}$ & $\begin{array}{l}\text { Upregulation in pancreatic, prostate, breast and ovarian cancer } \\
\text { (Garnham et al 2019). In cervical cancer is increased in metastatic } \\
\text { cancer and its levels correlate with stromal invasion, metastatic } \\
\text { spread to the lymph nodes and poor patient prognosis (Wang et al } \\
\text { 2002; Wang et al 2003) }\end{array}$ \\
\hline
\end{tabular}




\section{Table 2 (on next page)}

Glycogenes downregulated in cervical cancer patients and aberrantly expressed in several types of cancers. 


\section{Table 2. Glycogenes that are downregulated in cervical cancer patients and their aberrant 2 expression in several types of cancers.}

\begin{tabular}{lll}
\hline Glycogene & \multicolumn{1}{c}{ Enzyme function } & Reports in cancer patients \\
\hline & $\begin{array}{l}\text { Glycogen synthase that transfers the glycosyl } \\
\text { residue from UDP-Glc to the non-reducing end of } \\
\text { alpha-1,4-glucan. }\end{array}$ & $\begin{array}{l}\text { Overexpression of GYS1 along with MIF is associated with adverse } \\
\text { outcome in acute myeloid leukaemia (Falantes et al 2015) }\end{array}$
\end{tabular}

Carbohydrate sulfotransferase 12 that transfers sulfate to position 4 of the $\mathrm{N}$-acetylgalactosamine (GalNAc) residue of chondroitin and desulfated dermatan sulfate

Hydrolyze of N-acetyl-beta-D-glucosamine (1-4)N

$C T B S$ acetylglucosamine chitobiose core from the reducing end of the bond.

No reported as altered in cancer patients

Hyaluronan synthase 3 catalyzes the addition of

HAS3 GlcNAc or GlcUA monosaccharides to the nascent hyaluronan polymer.

Heparanase That cleaves heparan sulfate

HPSE proteoglycans into heparan sulfate side chains and core proteoglycans

Hyaluronidase-2 that hydrolyzes high molecular

HYAL2 weight hyaluronic acid to produce an intermediatesized product 2015) bladder (Chang et al 2015)
High expression of mRNA in ovarian cancer (Oliviera-Ferrer et al

HAS3 underexpression is associated with poor prognosis in patients with urothelial carcinoma of the upper urinary tract and urinary

The positive expression is associated with prognosis in ovarian cancer (Zhang et al 2013). Expression levels are associated with tumor size, histology grade and pathological stage in breast cancer (Tang et al 2014). High levels of HPSE is associated with shorter survival of patients with high-grade glioma (Kundu et al 2016)

Expression of HYAL2 is negatively correlated with lymphatic metastasis and TNM stage in colorectal cancer (Jin et al 2019). Combined expression of HYAL2 and S100P is associated with shorter progression-free survival, recurrence events, and occurrence of metastasis (Maierthaler et al 2015). HYAL2 along with other four genes discriminated progressive from non-progressive bladder cancer patients (van der Heijden et al 2016). Reduced HYAL1 expression was associated with the progression of endometrial carcinomas and deep myometrial invasion (Nykopp et al 2015)

$\mathrm{N}$-acetylgalactosaminyltransferase 11 that catalyzes GALNT11 expression is associated disease prognosis (Libisch et al the initiation of protein O-linked glycosylation

GALNT11

$U G T 2 B 4$

UDP-glucuronosyltransferase 2B4 that transfer glucoronate to an acceptor to produce an acceptor $\beta-$ D-glucuronoside
2014)

Increased in hepatocellular carcinoma and colorectal cancer patients (Kondoh et al 1999; Sayagués et al 2016) UDP-glucuronosyltransferase 2B28 that transfer Not reported as aberrantly expressed in cancer but genomic
glucoronate to an acceptor to produce an acceptor $\beta$ - variation is associated with ages of hepatocellular carcinoma D-glucuronoside occurrence and life expectancy (Le et al 2019) 
Table 3 (on next page)

Clinical characteristics of 297 cervical cancer patients evaluated by RNA-seq analysis. 
1 Table 3. Clinical characteristics of 209 samples of cervical cancer patients evaluated in the RNAseq analysis.

\begin{tabular}{|c|c|c|c|c|c|c|c|c|c|c|c|c|c|c|}
\hline & \multirow[b]{2}{*}{$\mathbf{n}$} & \multicolumn{5}{|c|}{ Stage } & \multicolumn{6}{|c|}{ Tumor differentiation grade } & \multicolumn{2}{|c|}{$\begin{array}{c}\text { Overall survival } \\
\text { status }\end{array}$} \\
\hline & & $\mathbf{I}$ & II & III & IV & $\begin{array}{l}\text { No } \\
\text { data }\end{array}$ & G1 & G2 & G3 & G4 & GX & $\begin{array}{l}\text { No } \\
\text { data }\end{array}$ & Living & Deceased \\
\hline $\begin{array}{r}\text { Squamous Cell } \\
\text { Carcinoma }\end{array}$ & 253 & 126 & 62 & 42 & 16 & 7 & 12 & 109 & 103 & 1 & 20 & 8 & 192 & 61 \\
\hline Adenocarcinoma & 44 & 30 & 7 & 3 & 4 & - & 5 & 25 & 11 & - & 3 & - & 34 & 10 \\
\hline
\end{tabular}


Table 4 (on next page)

Clinical characteristics of the squamous cervical cancer types according to their glycogene expression 
1 Table 4. Clinical characteristics of the squamous cervical cancer types according to their glycogene expression

\begin{tabular}{|c|c|c|c|c|c|c|c|c|c|c|c|c|c|c|c|c|}
\hline & \multicolumn{3}{|c|}{ Molecular classification } & \multicolumn{5}{|c|}{ Clinical stage classification } & \multicolumn{6}{|c|}{ Neoplasm histologic grade } & \multicolumn{2}{|c|}{$\begin{array}{c}\text { Overall survival } \\
\text { status }\end{array}$} \\
\hline & $\begin{array}{c}\text { Keratinizing } \\
\text { carcinoma }\end{array}$ & $\begin{array}{c}\text { Non- } \\
\text { keratinizing } \\
\text { carcinoma }\end{array}$ & $\begin{array}{l}\text { No } \\
\text { data }\end{array}$ & $\begin{array}{l}\text { Stage } \\
\text { I }\end{array}$ & $\begin{array}{l}\text { Stage } \\
\text { II }\end{array}$ & $\begin{array}{l}\text { Stage } \\
\text { III }\end{array}$ & $\begin{array}{l}\text { Stage } \\
\text { IV }\end{array}$ & $\begin{array}{l}\text { No } \\
\text { data }\end{array}$ & G1 & $\mathrm{G} 2$ & G3 & G4 & GX & $\begin{array}{l}\text { No } \\
\text { data }\end{array}$ & Alive & Deceased \\
\hline SCC-1 $(n=29)$ & 7 & 15 & 7 & 16 & 7 & 5 & 0 & 2 & 0 & 16 & 13 & 0 & 0 & 0 & 26 & 3 \\
\hline $\operatorname{SCC}-2(n=35)$ & 6 & 19 & 11 & 20 & 8 & 5 & 2 & 1 & 1 & 16 & 14 & 0 & 3 & 2 & 31 & 5 \\
\hline $\operatorname{SCC}-3(n=25)$ & 8 & 17 & 0 & 14 & 5 & 3 & 3 & 0 & 0 & 9 & 13 & 0 & 3 & 0 & 17 & 8 \\
\hline SCC-4 $(n=23)$ & 6 & 17 & 0 & 14 & 5 & 4 & 0 & 0 & 0 & 13 & 9 & 0 & 1 & 0 & 18 & 5 \\
\hline $\operatorname{SCC}-5(n=10)$ & 3 & 7 & 0 & 9 & 0 & 1 & 0 & 0 & 1 & 1 & 8 & 0 & 0 & 0 & 5 & 5 \\
\hline $\operatorname{SCC}-6(n=9)$ & 0 & 9 & 0 & 3 & 3 & 1 & 2 & 0 & 0 & 4 & 4 & 0 & 1 & 0 & 8 & 1 \\
\hline
\end{tabular}

2 


\section{Table 5 (on next page)}

Glycogenes that are exclusively expressed in cervical adenocarcinoma and subtypes of squamous carcinoma. 
1 Table 5. Glycogenes that are exclusively expressed in cervical adenocarcinoma and 2 subtypes of squamous carcinoma.

\begin{tabular}{|c|c|c|c|c|}
\hline \multirow{2}{*}{ Adenocarcinoma } & \multicolumn{4}{|c|}{ Squamous carcinoma } \\
\hline & SCC-1 and SCC-4 & SCC-3 & SCC-5 & SCC-6 \\
\hline ALG11 & $A L G 3$ & CHST2 & B4GALT1 & $A R S B$ \\
\hline ALG12 & ALG5 & COLGALT1 & C1GALT1 & B3GALNT1 \\
\hline ALG9 & $A M D H D 2$ & DSE & CHST11 & B3GNT2 \\
\hline$A M Y 1 A$ & ARSA & EXT1 & CHST15 & B4GALT6 \\
\hline$A M Y 2 A$ & B3GALT6 & EXT2 & CSGALNACT1 & CHSY3 \\
\hline$A M Y 2 B$ & B3GAT3 & GALNT18 & GALNT2 & CTBS \\
\hline$A R S D$ & B4GALT2 & & GFPT2 & DPY19L1 \\
\hline ARSE & B4GALT7 & & UAP1 & DSEL \\
\hline B3GALT5 & CHPF2 & & & EXTL1 \\
\hline B3GAT1 & CHST12 & & & EXTL2 \\
\hline B3GNT3 & $D A D 1$ & & & GALNT13 \\
\hline B3GNT7 & DPM2 & & & GALNT15 \\
\hline CHST4 & DPM3 & & & GALNT17 \\
\hline CHST6 & EDEM2 & & & GCNT1 \\
\hline CYB5R3 & GALK1 & & & GLCE \\
\hline DPAGT1 & GNPTG & & & GLT8D2 \\
\hline GAL3ST1 & GPAA1 & & & GNS \\
\hline GAL3ST2 & GUSB & & & GXYLT1 \\
\hline GALNT12 & HEXA & & & GXYLT2 \\
\hline GALNT4 & HEXD & & & GYG1 \\
\hline GALNT6 & MAN1B1 & & & HS2ST1 \\
\hline GALNT9 & MANBAL & & & $K L$ \\
\hline GALNTL6 & MOGS & & & $L F N G$ \\
\hline GBA3 & NAGLU & & & MAN1A1 \\
\hline GCNT2 & NAGPA & & & PIGK \\
\hline GCNT3 & NANS & & & POFUT1 \\
\hline GLB1L & NT5M & & & ST3GAL2 \\
\hline GMDS & OST4 & & & ST6GAL2 \\
\hline$G N E$ & $P I G Q$ & & & ST6GALNAC3 \\
\hline GYG2 & PIGU & & & ST6GALNAC5 \\
\hline MGAT3 & PMM1 & & & ST8SIA2 \\
\hline$N A G A$ & POMT1 & & & SULF1 \\
\hline NEU4 & RFNG & & & TUSC3 \\
\hline POFUT2 & RPN1 & & & UGGT1 \\
\hline PYGB & RPN2 & & & UGGT2 \\
\hline ST6GALNAC1 & ST3GAL3 & & & UXS1 \\
\hline ST6GALNAC4 & SUMF2 & & & \\
\hline ST6GALNAC6 & TSTA3 & & & \\
\hline \multicolumn{5}{|l|}{ STT3A } \\
\hline \multicolumn{5}{|l|}{ SULT1C2 } \\
\hline \multicolumn{5}{|l|}{ TREH } \\
\hline UGT2B7 & & & & \\
\hline
\end{tabular}

3 